\title{
Clinical validation of cutoff target ranges in newborn screening of metabolic disorders by tandem mass spectrometry: A worldwide collaborative project
}

David M. S. McHugh ${ }^{1}$, Cynthia A. Cameron, PhD'2, Jose E. Abdenur, MD ${ }^{3}$, Mahera Abdulrahman, MD, PhD , Ona Adair, PhD ${ }^{5}$, Shahira Ahmed Al Nuaimi, BSc ${ }^{4}$, Henrik Åhlman, MSc ${ }^{6}$, Jennifer J. Allen, RN, BSN $N^{7}$, Italo Antonozzi, MD ${ }^{8}$, Shaina Archer, MSc',

Sylvia Au, MS $S^{10}$, Christiane Auray-Blais, PhD ${ }^{11}$, Mei Baker, MD ${ }^{12}$, Fiona Bamforth, MD ${ }^{9}$, Kinga Beckmann ${ }^{13}$, Gessi Bentz Pino, MS ${ }^{l}$,

Stanton L. Berberich, PhD ${ }^{14}$, Robert Binard, BS ${ }^{15}$, François Boemer, PharmD, PhD ${ }^{16}$, Jim Bonham, PhD ${ }^{17}$, Nancy N. Breen, MT ${ }^{18}$, Sandra C. Bryant, MS $S^{1}$, Michele Caggana, ScD ${ }^{19}$, S. Graham Caldwell ${ }^{20}$, Marta Camilot, PhD ${ }^{21}$, Carlene Campbell ${ }^{22}$, Claudia Carducci, MS ${ }^{8}$, Rohit Cariappa, PhD ${ }^{33}$, Clover Carlisle ${ }^{24}$. Ubaldo Caruso ${ }^{25}$, Michela Cassanello, PhChem ${ }^{25}$, Ane Miren Castilla ${ }^{26}$,

Daisy E. Castiñeiras Ramos ${ }^{27}$, Pranesh Chakraborty, PhD ${ }^{28}$, Ram Chandrasekar, PhD ${ }^{29}$, Alfredo Chardon Ramos ${ }^{30}$, David Cheillan, PhD ${ }^{31}$

Yin-Hsiu Chien, MD, PhD ${ }^{32}$, Thomas A. Childs ${ }^{33}$, Petr Chrastina, MSc ${ }^{34}$, Yuri Cleverthon Sica, MSc ${ }^{35}$, Jose Angel Cocho de Juan, PhD ${ }^{27}$,

Maria Elena Colandre, PhD ${ }^{36}$, Veronica Cornejo Espinoza, MSc ${ }^{37}$. Gaetano Corso, MD ${ }^{38}$, Robert Currier, PhD ${ }^{39}$, Denis Cyr, MSc ${ }^{11}$, Noemi Czuczy, MSc'40, Oceania D'Apolito, PhD ${ }^{38}$, Tim Davis, BS ${ }^{41}$, Monique G. de Sain-Van der Velden, PhD ${ }^{42}$,

Carmen Delgado Pecellin, PhD ${ }^{43}$, Iole Maria Di Gangi, PhD ${ }^{44}$, Cristina Maria Di Stefano, MD ${ }^{45}$, Yannis Dotsikas, PhD ${ }^{46}$

Melanie Downing, MSc ${ }^{17}$, Stephen M. Downs, PhD ${ }^{47}$, Bonifacio Dy, MD ${ }^{48}$, Mark Dymerski ${ }^{49}$, Inmaculada Rueda, MD ${ }^{50}$, Bert Elvers $^{51}$,

Roger Eaton, PhD ${ }^{52}$, Barbara M. Eckerd ${ }^{53}$, Fatma El Mougy, MD ${ }^{54}$, Sarah Eroh ${ }^{55}$, Mercedes Espada, PhD ${ }^{26}$, Catherine Evans, PhD ${ }^{56}$,

Sandy Fawbush, RN, BSN ${ }^{57}$, Kristel F. Fijolek ${ }^{53}$, Lawrence Fisher ${ }^{28}$, Leifur Franzson, PhD ${ }^{58}$, Dianne M. Frazier, PhD ${ }^{59}$, Luciana R. C. Garcia ${ }^{60}$,

Maria Sierra García-Valdecasas Bermejo, PhD ${ }^{43}$, Dimitar Gavrilov, MD, PhD ${ }^{I}$, Rosemarie Gerace, BSc ${ }^{61}$, Giuseppe Giordano, PhD ${ }^{44}$,

Yolanda González Irazabal ${ }^{62}$, Lawrence C. Greed, $B S c^{63}$, Robert Grier, PhD ${ }^{64}$, Elyse Grycki, $M S^{1}$, Xuefan Gu, PhD ${ }^{65}$,

Fizza Gulamali-Majid, PhD ${ }^{66}$, Arthur F. Hagar, PhD ${ }^{67}$, Lianshu Han, MD ${ }^{65}$, W. Harry Hannon, PhD ${ }^{68}$, Christa Haslip ${ }^{69}$

Fayza Abdelhamid Hassan, MD ${ }^{54}$, Miao He, PhD ${ }^{70}$, Amy Hietala ${ }^{71}$, Leslie Himstedt, BSMT (ASCP) ${ }^{55}$, Gary L. Hoffman ${ }^{13}$,

William Hoffman, BS ${ }^{41}$, Philis Hoggatt ${ }^{72}$, Patrick V. Hopkins ${ }^{22}$, David M. Hougaard, MD ${ }^{73}$, Kerie Hughes ${ }^{2}$, Patricia R. Hunt ${ }^{74}$,

Wuh-Liang Hwu, MD ${ }^{32}$, June Hynes ${ }^{75}$, Isabel Ibarra-González, MSc ${ }^{76}$, Cindy A. Ingham, RN, BSN ${ }^{77}$, Maria Ivanova, PhD ${ }^{78}$, Ward B. Jacox ${ }^{79}$,

Catharine John, PhD ${ }^{80}$, John P. Johnson, MD ${ }^{81}$, Jón J. Jónsson, MD, PhD ${ }^{58}$, Eszter Karg, MD, PhD ${ }^{82}$, David Kasper, PhD ${ }^{83}$, Brenda Klopper ${ }^{84}$, Dimitris Katakouzinos, PhD ${ }^{85}$, Issam Khneisser, MS ${ }^{86}$, Detlef Knoll, MSc ${ }^{87}$, Hirinori Kobayashi, MD, PhD ${ }^{88}$, Ronald Koneski ${ }^{74}$,

Viktor Kožich, MD, PhD ${ }^{34}$, Rasoul Kouapei, PhD ${ }^{89}$, Dirk Kohlmueller, PhD ${ }^{90}$, Ivo Kremensky, MD, PhD ${ }^{78}$, Giancarlo la Marca, Pharm Sc ${ }^{91}$,

Marcia Lavochkin $^{92}$, Soo-Youn Lee, MD, PhD ${ }^{93}$, Denis C. Lehotay, PhD ${ }^{94}$, Aida Lemes, MD ${ }^{95}$, Joyce Lepage ${ }^{94}$, Barbara Lesko, MT ${ }^{18}$

Barry Lewis, MD ${ }^{63}$, Carol Lim, BSc $c^{96}$, Sharon Linard, MS ${ }^{29}$, Martin Lindner, MD ${ }^{90}$, Michele A. Lloyd-Puryear, MD ${ }^{97}, F r e d ~ L o r e y, ~ P h D^{39}$,

Yannis L. Loukas, PhD ${ }^{46}$, Julie Luedtke ${ }^{98}$, Neil Maffitt ${ }^{l}$, J. Fergall Magee, MD ${ }^{89}$, Adrienne Manning ${ }^{99}$, Shawn Manos, $B S^{I 00}$,

Sandrine Marie, PhD ${ }^{101}$, Sônia Marchezi Hadachi ${ }^{60}$, Gregg Marquardt ${ }^{\prime}$, Stephen J. Martin, PhD ${ }^{56}$, Dietrich Matern, MD ${ }^{I}$

Stephanie K. Mayfield Gibson, MD ${ }^{57}$, Philip Mayne, MD ${ }^{102}$, Tonya D. McCallister, MS, MPH ${ }^{7}$, Mark McCann, $B A^{71}$, Julie McClure, MPH ${ }^{59}$,

James J. McGill, MBBS ${ }^{103}$, Christine D. McKeever ${ }^{33}$, Barbara McNeilly ${ }^{104}$, Mark A. Morrissey, PhD ${ }^{19}$, Paraskevi Moutsatsou, PhD ${ }^{105}$,

Eleanor A. Mulcahy, RNC ${ }^{106}$, Dimitris Nikoloudis, MSc ${ }^{107}$, Bent Norgaard-Pedersen, MD ${ }^{73}$, Devin Oglesbee, PhD ${ }^{1}$, Mariusz Oltarzewski, PhD ${ }^{108}$,

Daniela Ombrone ${ }^{109}$, Jelili Ojodu, MPH ${ }^{110}$, Vagelis Papakonstantinou, PhD ${ }^{85}$, Sherly Pardo Reoyo, MD ${ }^{30}$, Hyung-Doo Park, MD, PhD ${ }^{93}$,

Marzia Pasquali, PhD ${ }^{11}$, Elisabetta Pasquini, MD ${ }^{91}$, Pallavi Patel ${ }^{112}$, Kenneth A. Pass, PhD ${ }^{113}$, Colleen Peterson ${ }^{100}$,

Rolf D. Pettersen, PhD ${ }^{114}$, James J. Pitt, PhD ${ }^{115}$, Sherry Poh, MSc ${ }^{80}$, Arnold Pollak, MD ${ }^{83}$, Cory Porter ${ }^{49}$, Philip A. Poston, PhD ${ }^{116}$,

Ricky W. Price, BSc ${ }^{117}$, Cecilia Queijo, BS $S^{95}$, Jonessy Quesada, MD ${ }^{118}$, Edward Randell, PhD ${ }^{75}$, Enzo Ranieri, PhD ${ }^{61}$,

Kimiyo Raymond, $M D^{1}$, John E. Reddic, PhD ${ }^{20}$, Alejandra Reuben ${ }^{118}$, Charla Ricciardi, $B S^{119}$, Piero Rinaldo, MD, PhD ${ }^{\prime}$,

Jeff D. Rivera, PhD ${ }^{120}$, Alicia Roberts, MS ${ }^{121}$, Hugo Rocha, MSc ${ }^{122}$, Geraldine Roche, MSc ${ }^{102}$, Cheryl Rochman Greenberg, MD ${ }^{123}$,

José María Egea Mellado, PhD ${ }^{124}$, María Jesús Juan-Fita, PhD ${ }^{124}$, Consuelo Ruiz ${ }^{125}$, Margherita Ruoppolo, MD ${ }^{109}$, S. Lane Rutledge, MD ${ }^{121}$,

Euijung Ryu, PhD ${ }^{1}$, Christine Saban, PhD ${ }^{31}$, Inderneel Sahai, MD ${ }^{52}$, Maria Isabel Salazar García-Blanco ${ }^{62}$, Pedro Santiago-Borrero, MD ${ }^{30}$,

Andrea Schenone, PhD ${ }^{36}$, Roland Schoos, PhD ${ }^{16}$, Barb Schweitzer, $R N^{126}$, Patricia Scott ${ }^{24}$, Margretta R. Seashore, $M D^{127}$

Mary A. Seeterlin, PhD ${ }^{128}$, David E. Sesser ${ }^{129}$, Darrin W. Sevier ${ }^{57}$, Scott M. Shone, PhD ${ }^{12}$, Graham Sinclair, PhD ${ }^{130}$,

Victor A. Skrinska, PhD ${ }^{131}$, Eleanor L. Stanley, BS, MT $(A S C P)^{128}$, Erin T. Strovel, PhD ${ }^{132}$, April L. Studinski Jones, MS ${ }^{1}$,

Sherlykutty Sunny, $B S^{19}$, Zoltan Takats, $P h D^{40}$, Tijen Tanyalcin, $M D$, PhD ${ }^{133}$, Francesca Teofoli ${ }^{11}$, J. Robert Thompson, BSc ${ }^{123}$,

Kathy Tomashitis, MNS ${ }^{20}$, Mouseline Torquado Domingos ${ }^{35}$, Jasmin Torres ${ }^{48}$, Rosario Torres ${ }^{125}$, Silvia Tortorelli, MD, PhD,

Sandor Turi, $M D$, PhD ${ }^{82}$, Kimberley Turner, $R N^{134}$, Nick Tzanakos ${ }^{115}$, Alf G. Valiente, $P h D^{37}$, Hillary Vallance, $M D^{130}$,

Marcela Vela-Amieva, $M D^{135}$, Laura Vilarinho, $P h D^{122}$. Ulrika von Döbeln, MD, PhD ${ }^{6}$, Marie-Francoise Vincent, MD, PhD ${ }^{101}$,

B. Chris Vorster, FCPath ${ }^{84}$, Michael S. Watson, PhD ${ }^{136}$, Dianne Webster, PhD ${ }^{87}$, Sheila Weiss, MS ${ }^{41}$, Bridget Wilcken, MD ${ }^{96}$,

Veronica Wiley, PhD ${ }^{96}$, Sharon K. Williams, MS ${ }^{137}$, Sharon A. Willis, BS, MT (ASCP) ${ }^{129}$, Michael Woontner, PhD ${ }^{15}$, Katherine Wright ${ }^{138}$,

Raquel Yahyaoui, $M D^{50}$, Seiji Yamaguchi, MD ${ }^{88}$, Melissa Yssel, MB ChB, FC Path(SA) Chem ${ }^{139}$, and Wendy M. Zakowicz, BS

Purpose: To achieve clinical validation of cutoff values for newborn
screening by tandem mass spectrometry through a worldwide collaborative
effort. Methods: Cumulative percentiles of amino acids and acylcarnitines

See Acknowledgements for author affiliation.

Piero Rinaldo, MD, PhD, Department of Laboratory Medicine and Pathology, Biochemical Genetics Laboratory, Hilton 530B, Mayo Clinic College of Medicine, 200 First Street SW, Rochester, MN 55905. E-mail: rinaldo@mayo.edu.

Disclosure: The authors declare no conflict of interest.

Submitted for publication December 2, 2010.

Accepted for publication December 27, 2010.

Published online ahead of print February 15, 2011.

DOI: $10.1097 /$ GIM.0b013e31820d5e67 in dried blood spots of approximately 25-30 million normal newborns and 10,742 deidentified true positive cases are compared to assign clinical significance, which is achieved when the median of a disorder range is, and usually markedly outside, either the 99th or the 1st percentile of the normal population. The cutoff target ranges of analytes and ratios are then defined as the interval between selected percentiles of the two populations. When overlaps occur, adjustments are made to maximize sensitivity and specificity taking all available factors into consideration. Results: As of December 1, 2010, 130 sites in 45 countries have uploaded a total of 25,114 percentile data points, 565,232 analyte results of true positive cases with 64 conditions, and 5,341 cutoff values. The average rate of submission of true positive cases between December 1, 2008, and December 1, 2010, was 5.1 cases/day. This cumulative evidence generated 91 high and 23 low cutoff target ranges. The overall proportion of cutoff values within the respective 
target range was $42 \%(2,269 / 5,341)$. Conclusion: An unprecedented level of cooperation and collaboration has allowed the objective definition of cutoff target ranges for 114 markers to be applied to newborn screening of rare metabolic disorders. Genet Med 2011:13(3):230-254.

Key Words: acylcarnitines, amino acids, inborn errors of metabolism, newborn screening, tandem mass spectrometry

$S^{i}$ ince the publication of the recommendations by an expert panel assembled by the American College of Medical Genetics (ACMG), ${ }^{1}$ substantial progress has been made in the adoption of the uniform newborn screening panel by public health programs, culminating in their recent ratification by the US Secretary of Health and Human Services as a national standard. ${ }^{2}$ A major contribution to the expansion process has come from the Regional Genetics and Newborn Screening Collaboratives funded by the Health Resources and Service Administration of the Maternal and Child Health Bureau. ${ }^{3}$ The main goal of these projects has been to enhance and support the genetics and newborn screening capacity across the nation by undertaking a regional approach toward addressing the maldistribution of genetic resources. Notably, to be eligible for funding a regional proposal had to include at least four participating states. The initial application for Region 4 (principal investigator: Cynthia A. Cameron, $\mathrm{PhD}$ ) involved all seven states in the region (Illinois, Indiana, Kentucky, Michigan, Minnesota, Ohio, and Wisconsin) and included a project to facilitate the universal implementation of newborn screening by tandem mass spectrometry (MS/MS) and confirmatory testing of newborns for inborn errors of amino acid, organic acid, and fatty acid metabolism. The specific objectives of this project were (a) to achieve uniformity of testing panels by MS/MS to maximize detection of affected newborns within the region; (b) to improve overall analytical performance; and (c) to set and sustain the lowest achievable rates of false positive and false negative results. The last two objectives were chosen as part of an effort to call more attention to "how well" conditions are screened for, ${ }^{4}$ as an alternative to merely counting "how many" of them are included in the panel of a given program. ${ }^{5}$ The rationale for this work also came from the need to address the considerable confusion, and, at times, vigorous controversy about the scientific basis of the uniform panel, ${ }^{6-9}$ and speculations of severe consequences of poor performance. ${ }^{10}$ When dealing with rare disorders, even long-term experiences of single sites ${ }^{11,12}$ are unlikely to generate adequate evidence for many if not most conditions, so it became apparent that only an unprecedented level of cooperation and collaboration among providers of screening services could lead to the creation of a body of evidence adequate for the clinical validation of cutoff values for most if not all markers measured by MS/MS

Since its 2005 launch on a regional basis, this project has grown nationally and also internationally with the active participation of 48 US states and territories, plus 80 programs in 45 other countries. A milestone of this project took place in November 2008 when the Region 4 Stork (R4S) website went live (http://www.region4genetics.org/msms_data_project), ending the cumbersome use of offline spreadsheets. The website allows users to submit data independently and to have on demand access to up-to-date tools and reports based on the entire body of collective experience.

For the first time, we describe in this study the disorder ranges for amino acids, acylcarnitines, and related ratios in a total of 64 conditions. This group includes the 20 primary conditions in the ACMG uniform panel (detected by MS/MS),
21 of the 22 secondary targets, eight maternal conditions (leading to secondary abnormalities in the screening profile of the newborn), and 15 other conditions that manifest with biochemical phenotypes mimicking those of primary and/or secondary targets. The disorder ranges are then linked to cumulative population percentile data to define high and, when applicable, low cutoff target ranges. These ranges are automatically updated after any new submission and are available on demand to participants through a web-based interface.

\section{MATERIALS AND METHODS}

\section{Participating sites}

The collaborative project started in June 2005. As of December 1, 2010, the status of the United States and international participation is shown in Figure 1, A and B. Forty-seven US states and Puerto Rico are active participants. International participation includes 80 programs in 45 countries. Most sites have one primary contact, the user with read/write access to the project website who is responsible for data submission. The professional background of other users with read-only access span over a large variety of roles, including program directors, laboratory supervisors and technologists, follow-up coordinators, genetic counselors, dieticians, residents, fellows training in genetics, and a growing number of metabolic specialists who are providers of patient care. The total number of users with an active password is 602 (range: 1-53 per US site, average $8 ; 1-14$ per international site, average 4), double the earliest available count $(N=300)$ that was recorded in June 2009.

\section{R4S website}

$\mathrm{R} 4 \mathrm{~S}$ is a custom-designed and -coded application for the collection and reporting of possibly any type of newborn screening data based on numerical results. The system is a web-based application that implements a three-tier client-server architectural model. The client or presentation tier is the user interface, which can be accessed using popular web browsers from any computer with internet access. The R4S software is compatible with Internet Explorer 6+ and Firefox 2+ (as well as other browsers such as Safari, Opera, and Chrome). The logic and business tier applications are located on a web server and implementing Microsoft Internet Information Server version 6. The application code is written in ASP and C\# for Microsoft .NET version 3.5. Winnovative HTML to PDF Converter version 4.0 for .NET and dotnetCharting version 5.3 are used by the web software for pdf and chart generation, respectively. The data tier, located on a database server, uses Microsoft SQL Server 2008 with custom-written T-SQL stored procedures.

Over the last 5 years this project has evolved into an organized, web-based data collection system with a computer program tailored to meet the needs of a diverse population of users. National and international participants are provided with a user ID and password to gain access to a secure section of the R4S website. Once logged in, users have access to profiles unique to their screening program for data submission and to comparison tools, as well as to common folders inclusive of more than 30 project tools and reports. Access to the MS/MS application can be personalized for individual users, including read/write (or read only) privileges and administrative oversight. The database is set to automatically perform basic calculation of descriptive statistics, particularly the calculation of predefined percentiles. These values (and the number of data 

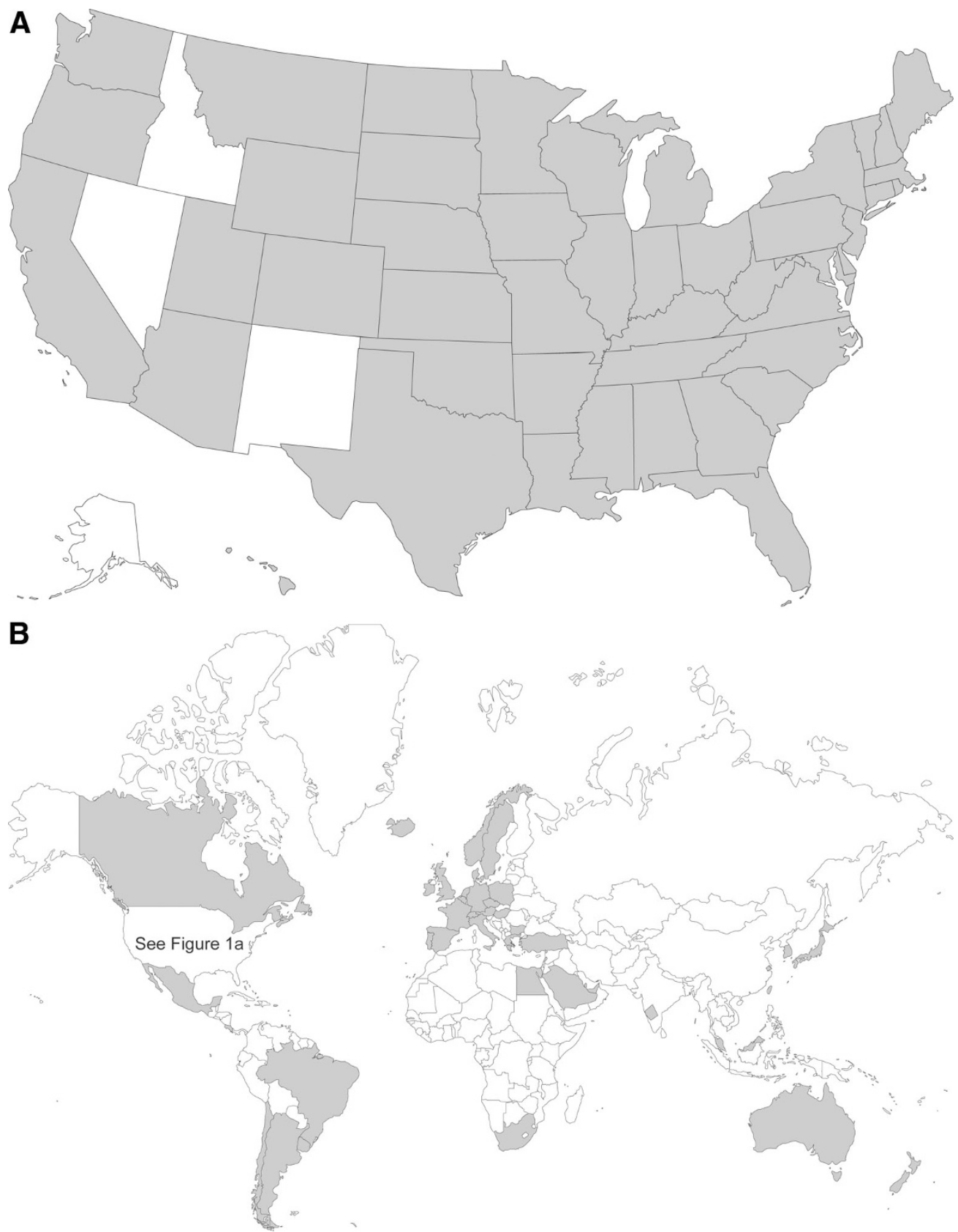

Fig. 1. Status of the R4S collaborative project as of December 1, 2010. Gray color indicates active participation. A, Participants in the United States. B, Worldwide participants. In countries outside of the United States, multiple sites may be involved.

points used to calculate them) are automatically linked to descriptive and comparative tools, which will be described in complete details elsewhere.

\section{Data submission}

Participants submit five types of data: (a) five selected percentiles of individual markers and ratios in the normal population; (b) all cutoff values used in routine screening practice; (c) the complete set of available amino acid and acylcarnitine results in true positive cases (according to case definition as established by local protocols and/or professional guidelines; for example, the ACMG act sheets ${ }^{13}$ ); (d) performance metrics (detection rate, false positive rate, and positive predictive value $^{4}$ ), and (e) answers to a series of multiple choice questions to define a participant profile (e.g., source of reagents, use of derivatization, date of collection, and punch size). On average, 25-30 users log-in daily ( $\sim 40 \%$ are international), ranging from 0 to 145 in a given day.

\section{Percentiles}

Five percentile values $(1 \%, 10 \%, 50 \%, 90 \%$, and $99 \%)$ of each marker are calculated by standard statistical methods. 


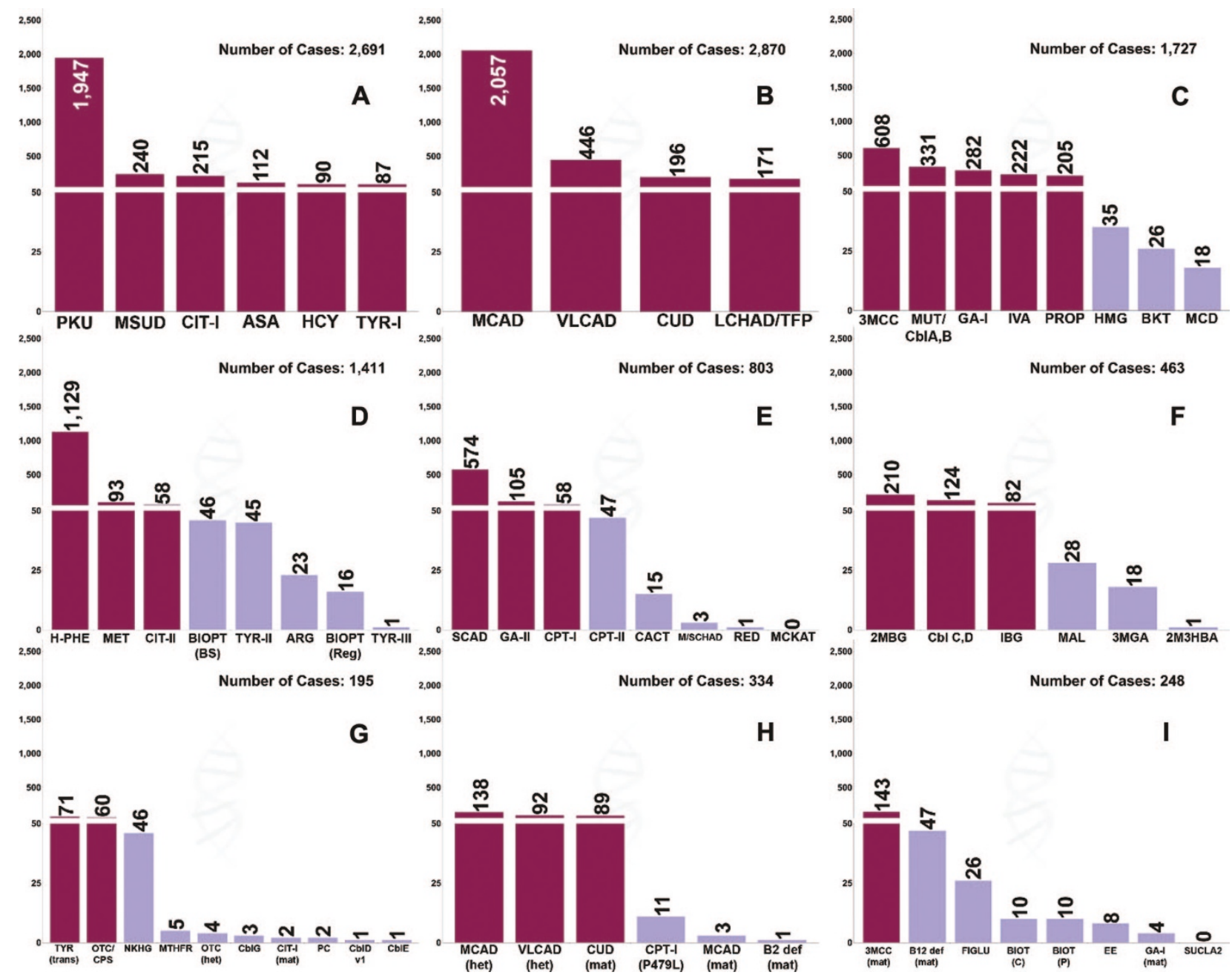

Fig. 2. Number of available cases per condition as of December 1, 2010, sorted in descending order. The split scale on the $Y$-axis and the darker color are used to highlight those conditions with at least 50 cases, the initial goal of the collaborative project. Panels A-C: primary targets of the ACMG uniform panel; panels D-F: secondary targets; and panels G-I: other conditions, including carriers and maternal conditions. Left column: amino acid disorders; middle column: fatty acid oxidation disorders; and right column: organic acid disorder. Abbreviations (in alphabetical order): 2M3HBA, 2-methyl 3-hydroxybutyrylCoA dehydrogenase deficiency (OMIM number 300438); 2MBG, 2-short/branched chain acyl-CoA dehydrogenase deficiency (610006); 3MCC, 3-methylcrotonyl-CoA carboxylase deficiency (210200,210210); 3MGA, 3-methylglutaconyl-CoA hydratase deficiency (250950); ARG, argininemia (207800); ASA, argininosuccinic acidemia (207900); B12 def, vitamin B12 deficiency; BIOPT (Reg), disorders of biopterin regeneration (261630); BIOPT (BS), disorders of biopterin biosynthesis (261640); BKT, $\beta$-ketothiolase deficiency (203750); CACT, carnitine:acylcarnitine translocase deficiency (212138); Cbl, cobalamin (complementation group); CIT-I, citrullinemia type I (215700); CIT-II, citrullinemia type II (605814,603471); CPT-I, carnitine palmitoyltransferase la deficiency (255120); CPT-II, carnitine palmitoyltransferase II deficiency (255110); CPS, carbamylphosphate synthase deficiency (237300); CUD, carnitine uptake defect (212140); EE, ethylmalonic encephalopathy (602473); FIGLU, formiminoglutamic acidemia (229100); GA-II, glutaric acidemia type II (608053, 130410, 231675); GA-I, glutaric acidemia type I (231670); H-PHE, hyperphenylalaninemia (261600); HCY, homocystinuria (236200); het, heterozygote (carrier status); HMG, 3-hydroxy-3-methylglutaryl-CoA lyase deficiency (300438); IBG, isobutyryl-CoA dehydrogenase deficiency (611283); IVA, isovaleryl-CoA dehydrogenase deficiency (243500); LCHAD, long-chain L-3-Hydroxy dehydrogenase deficiency (609016); M/SCHAD, medium/short-chain L-3-hydroxy acyl-CoA dehydrogenase def. (601609); MAL, malonyl-CoA decarboxylase deficiency (248360); (mat), maternal; MCAD, medium-chain acyl-CoA dehydrogenase deficiency (607008); MCD, holocarboxylase synthetase deficiency (253270); MCKAT, medium-chain ketoacyl-CoA thiolase deficiency (602199); MET, hypermethioninemias (250850); MSUD, maple syrup urine disease (248600); MTHFR, methylene tetrahydrofolate reductase deficiency (607093); MUT, methylmalonic acidemia (251000, 251100, 251110); NKHG, nonketotic hyperglycinemia (605899); OTC, ornithine transcarbamylase deficiency (300461); PA, propionic acidemia (606054); PC, pyruvate carboxylase deficiency (266150); PKU, phenylketonuria (261600); RED, 2,4-dienoyl-CoA reductase deficiency (222745); SCAD, short-chain acyl-CoA dehydrogenase deficiency (201470); TFP, trifunctional protein deficiency (609015); TYR-I, tyrosinemia type I (276700); TYR-II, tyrosinemia type II (276600); TYR-III, tyrosinemia type III (276710); TYR (trans), transient tyrosinemia; VLCAD, very long-chain acyl-CoA dehydrogenase deficiency (201475). Condition codes are according to Watson et al. ${ }^{1}$ 
Table 1 Amino acid and acylcarnitine cumulative percentiles in neonatal dried blood spots analyzed by tandem mass spectrometry by participants of the Region 4 Stork collaborative project (as of December 1, 2010)

\begin{tabular}{|c|c|c|c|c|c|c|c|}
\hline \multirow{3}{*}{$\begin{array}{l}\text { Percentile } \\
\text { Marker }\end{array}$} & \multirow[b]{3}{*}{$N$} & \multicolumn{6}{|c|}{ Normal population $(\mu \mathrm{mol} / \mathrm{L})$} \\
\hline & & \multicolumn{2}{|c|}{$1 \%$ ile } & \multicolumn{2}{|c|}{$50 \%$ ile } & \multicolumn{2}{|c|}{ 99\%ile } \\
\hline & & Value & $\mathrm{CV}$ & Value & $\mathrm{CV}$ & Value & $\mathrm{CV}$ \\
\hline Ala & 58 & 117 & $22 \%$ & 233 & $19 \%$ & 507 & $22 \%$ \\
\hline $\operatorname{Arg}$ & 79 & 2.3 & $48 \%$ & 8.7 & $38 \%$ & 32 & $39 \%$ \\
\hline Asa & 26 & 0.04 & $140 \%$ & 0.19 & $98 \%$ & 0.66 & $94 \%$ \\
\hline Cit & 93 & 6.0 & $28 \%$ & 12 & $24 \%$ & 28 & $22 \%$ \\
\hline Glu & 27 & 158 & $37 \%$ & 294 & $31 \%$ & 551 & $30 \%$ \\
\hline Gln & 6 & 24 & $64 \%$ & 50 & $33 \%$ & 117 & $73 \%$ \\
\hline Gly & 60 & 185 & $40 \%$ & 348 & $34 \%$ & 767 & $30 \%$ \\
\hline Met & 94 & 11 & $29 \%$ & 21 & $22 \%$ & 44 & $25 \%$ \\
\hline Phe & 100 & 33 & $18 \%$ & 54 & $15 \%$ & 97 & $15 \%$ \\
\hline Suac & 22 & 0.21 & $85 \%$ & 0.66 & $54 \%$ & 1.4 & $84 \%$ \\
\hline Tyr & 97 & 34 & $19 \%$ & 80 & $16 \%$ & 207 & $17 \%$ \\
\hline Val & 86 & 57 & $18 \%$ & 103 & $18 \%$ & 212 & $20 \%$ \\
\hline Xle & 95 & 64 & $21 \%$ & 115 & $22 \%$ & 235 & $17 \%$ \\
\hline C0 & 93 & 11 & $28 \%$ & 24 & $25 \%$ & 59 & $26 \%$ \\
\hline $\mathrm{C} 2$ & 76 & 10 & $32 \%$ & 23 & $19 \%$ & 52 & $17 \%$ \\
\hline C3 & 93 & 0.57 & $28 \%$ & 1.75 & $20 \%$ & 4.74 & $20 \%$ \\
\hline $\mathrm{C} 4$ & 89 & 0.080 & $29 \%$ & 0.24 & $14 \%$ & 0.75 & $15 \%$ \\
\hline C5:1 & 81 & 0.001 & $145 \%$ & 0.021 & $56 \%$ & 0.080 & $59 \%$ \\
\hline C5 & 95 & 0.050 & $33 \%$ & 0.12 & $15 \%$ & 0.39 & $21 \%$ \\
\hline C4-OH (D) & 43 & 0.050 & $28 \%$ & 0.18 & $27 \%$ & 0.49 & $28 \%$ \\
\hline C4-OH \& C3-DC (U) & 11 & 0.040 & $52 \%$ & 0.12 & $56 \%$ & 0.33 & $66 \%$ \\
\hline C6 & 93 & 0.020 & $89 \%$ & 0.062 & $28 \%$ & 0.18 & $35 \%$ \\
\hline C5-OH (D) & 69 & 0.060 & $35 \%$ & 0.15 & $24 \%$ & 0.38 & $26 \%$ \\
\hline C5-OH \& C4DC (U) & 21 & 0.090 & $46 \%$ & 0.19 & $23 \%$ & 0.45 & $30 \%$ \\
\hline C6-OH (D) & 12 & 0.004 & $108 \%$ & 0.041 & $42 \%$ & 0.12 & $49 \%$ \\
\hline C8 & 97 & 0.020 & $78 \%$ & 0.070 & $21 \%$ & 0.21 & $23 \%$ \\
\hline C3-DC \& C8-OH (D) & 48 & 0.020 & $78 \%$ & 0.067 & $46 \%$ & 0.15 & $35 \%$ \\
\hline C10:2 & 48 & 0.001 & $125 \%$ & 0.020 & $59 \%$ & 0.08 & $55 \%$ \\
\hline C10:1 & 86 & 0.020 & $76 \%$ & 0.060 & $24 \%$ & 0.18 & $30 \%$ \\
\hline $\mathrm{C} 10$ & 92 & 0.022 & $28 \%$ & 0.090 & $19 \%$ & 0.26 & $22 \%$ \\
\hline C4-DC (D) & 26 & 0.12 & $64 \%$ & 0.28 & $55 \%$ & 0.71 & $49 \%$ \\
\hline C5-DC \& C10-OH (D) & 58 & 0.020 & $77 \%$ & 0.065 & $39 \%$ & 0.17 & $36 \%$ \\
\hline C5-DC \& C6-OH (U) & 18 & 0.020 & $86 \%$ & 0.095 & $54 \%$ & 0.25 & $47 \%$ \\
\hline $\mathrm{C} 12: 1$ & 58 & 0.010 & $88 \%$ & 0.063 & $33 \%$ & 0.27 & $31 \%$ \\
\hline C12 & 71 & 0.040 & $39 \%$ & 0.14 & $36 \%$ & 0.41 & $36 \%$ \\
\hline C6-DC & 64 & 0.022 & $88 \%$ & 0.070 & $50 \%$ & 0.17 & $45 \%$ \\
\hline $\mathrm{C} 14: 2$ & 68 & 0.010 & $82 \%$ & 0.036 & $44 \%$ & 0.090 & $43 \%$ \\
\hline
\end{tabular}


Table 1 Continued

\begin{tabular}{|c|c|c|c|c|c|c|c|}
\hline \multirow{3}{*}{$\begin{array}{l}\text { Percentile } \\
\text { Marker }\end{array}$} & \multirow[b]{3}{*}{$N$} & \multicolumn{6}{|c|}{ Normal population $(\mu \mathrm{mol} / \mathrm{L})$} \\
\hline & & \multicolumn{2}{|c|}{$1 \%$ ile } & \multicolumn{2}{|c|}{$50 \%$ ile } & \multicolumn{2}{|c|}{$99 \%$ ile } \\
\hline & & Value & $\mathrm{CV}$ & Value & $\mathrm{CV}$ & Value & $\mathrm{CV}$ \\
\hline C14:1 & 94 & 0.030 & $34 \%$ & 0.12 & $28 \%$ & 0.37 & $18 \%$ \\
\hline $\mathrm{C} 14$ & 90 & 0.071 & $34 \%$ & 0.23 & $17 \%$ & 0.50 & $17 \%$ \\
\hline $\mathrm{C} 16$ & 93 & 0.80 & $41 \%$ & 2.8 & $18 \%$ & 6.0 & $15 \%$ \\
\hline $\mathrm{C} 16: 1-\mathrm{OH}$ & 61 & 0.011 & $83 \%$ & 0.050 & $23 \%$ & 0.13 & $33 \%$ \\
\hline $\mathrm{C} 16-\mathrm{OH}$ & 94 & 0.010 & $99 \%$ & 0.030 & $39 \%$ & 0.08 & $40 \%$ \\
\hline $\mathrm{C} 18: 2$ & 63 & 0.060 & $33 \%$ & 0.18 & $27 \%$ & 0.60 & $32 \%$ \\
\hline C18:1 & 84 & 0.49 & $22 \%$ & 1.2 & $15 \%$ & 2.5 & $12 \%$ \\
\hline $\mathrm{C} 18$ & 83 & 0.31 & $29 \%$ & 0.81 & $16 \%$ & 1.7 & $15 \%$ \\
\hline C18:1-OH & 82 & 0.010 & $96 \%$ & 0.023 & $28 \%$ & 0.070 & $44 \%$ \\
\hline $\mathrm{C} 18-\mathrm{OH}$ & 66 & 0.001 & $248 \%$ & 0.020 & $42 \%$ & 0.060 & $57 \%$ \\
\hline
\end{tabular}

Ala, alanine; Arg, arginine; Asa, argininosuccinic acid; C0, free carnitine; C10:2, decadienoylcarnitine; C10:1, decenoylcarnitine; C10, decanoylcarnitine; C12:1, dodecenoylcarnitine; C12, dodecanoylcarnitine; C14:1, tetradecenoylcarnitine; C14, tetradecanoylcarnitine; C14:2, tetradecadienoylcarnitine; C16-OH, hydroxy palmitoylcarnitine; C16:1-OH, hydroxy hexadecenoylcarnitine; C16, palmitoylcarnitine; C18:1-OH, hydroxy oleylcarnitine; C18:2, linoleylcarnitine; C18:1, oleylcarnitine; $\mathrm{C} 18$, stearylcarnitine; $\mathrm{C} 18: 1-\mathrm{OH}$, hydroxy oleylcarnitine; $\mathrm{C} 18-\mathrm{OH}$, hydroxy stearylcarnitine; C2, acetylcarnitine; C3, propionylcarnitine; C3DC+C8-OH, malonyl-/ hydroxy octanoylcarnitine; $\mathrm{C} 4$, butyryl-/isobutyrylcarnitine; $\mathrm{C} 4-\mathrm{OH}$, hydroxy butyrylcarnitine; C4DC, succinyl-/methylmalonylcarnitine; C5, isovaleryl-/2-methylbutyrylcarnitine; $\mathrm{C} 5-\mathrm{OH}$, hydroxy isovalerylcarnitine; C5:1, tiglylcarnitine; C5DC + C10-OH, glutarylcarnitine plus hydroxy decanoylcarnitine; C6, hexanoylcarnitine; C6-OH, hydroxy hexanoylcarnitine; C6DC, methylglutarylcarnitine; $\mathrm{C} 8$, octanoylcarnitine; Cit, citrulline; CV, coefficient of variation (calculated from values within the interquartile range: median \pm [(75\%ile-25\%ile) $\times 1.5]$ ); (D), derivatized (see text for details); Gln, glutamine; Glu, glutamic acid; Gly, glycine; Met, methionine; $N$, number of participants who have submitted \%ile values; Phe, phenylalanine; Suac, succinylacetone; Tyr, tyrosine; (U), underivatized; Val, valine; Xle, isoleucine and leucine.

When requested, assistance with data processing has been provided to 26 participating sites who send the project coordinator anonymized raw data for calculation and submission on their behalf of percentile values. Data can be entered manually or, preferably, by a semiautomated procedure based on the uploading of a comma separated value file (.csv) suitable for data transmission using LOINC codes. ${ }^{14}$ As of December 1, 2010, a total of 25,108 percentile values have been submitted by 102 participants, $70 \%$ of them have updated their profile after January 1,2010 . The age of specimen collection was $24-48$ hours ( $57 \%$ of participating sites), 3 days $(34 \%)$, or 5 days $(9 \%)$. Each value is based on a variable number of cases, ranging from a few hundreds to more than 1 million. As an example, the current percentile values of the Minnesota program alone are derived from 517,283 newborns tested by MS/MS ${ }^{15}$ between July 1, 2004, and August 31, 2010. Although the total number of subjects included in the calculation of percentiles at each site is not consistently available, an extrapolation of the data collected for calculation of performance metrics (total numbers of true positives, false positives, false negatives, and true negatives; data have been submitted by $59 \%$ of participants) leads to an estimate of approximately 25-30 million individuals.

\section{Cutoff values}

The website is currently configured to upload 24 low and 90 high cutoff values. The standard unit is $\mu \mathrm{mol} / \mathrm{L}$. Data entry is manual only, divided into five categories: amino acids, amino acid ratios, acylcarnitines, acylcarnitine ratios, and second tier tests. The specific data of the latter group will not be discussed further in this study because they are not part of the primary screening by MS/MS. As of December 1, 2010, 5341 cutoff values (638 low and 4703 high, respectively) have been sub- mitted by 113 participants, $69 \%$ of them have posted and/or updated their profile since January 1, 2010. The number of active cutoffs varies considerably from site to site (range: 2-114, average 44), but there has been a steady trend to include additional cutoffs once the clinical utility of a given marker has been highlighted by the collaborative project. For example, 43 participants have added a low cutoff for the amino acid methionine in response to the emerging evidence of its clinical utility for the primary identification of asymptomatic newborns affected with remethylation disorders. ${ }^{16}$

\section{True positive cases}

The website is configured to upload newborn screening data of 25 amino acid disorders (6 primary targets of the ACMG uniform panel, 8 secondary targets, and 11 other conditions [6/8/11]), 18 fatty acid oxidation disorders (5/8/5), counting as separate conditions maternal cases and carriers for very longchain acyl-CoA dehydrogenase deficiency (OMIM number 201475) and medium-chain acyl-CoA dehydrogenase deficiency (MCAD, 607008), and 22 organic acid disorders (9/6/7). Figure 2 shows a summary of the number of cases entered into the R4S database (updated as of December 1, 2010). A total of 75 cases are annotated as false negatives (i.e., results that were reported as normal, but a diagnosis was made later based on clinical presentation), it is more than likely that a larger number of false negative cases were submitted but not disclosed. Nonketotic hyperglycinemia (OMIM\# 605899), tyrosinemia type I (OMIM\# 276700), ornithine transcarbamylase deficiency (OMIM\# 300461), and different types of methylmalonic acidemia (Cbl A,B; OMIM\# 251000, 2511100, 251110) are the conditions with greater representation in the false negative group. The database also includes 670 cases $(6.3 \%)$ extracted 
from the literature. These cases are not duplicate entries because they were published by laboratories who have declined invitations to be active participants of the collaborative project. Conditions are sorted in descending order by group (left: amino acid disorders; center: fatty acid oxidation disorders; and right: organic acid disorders) and by status in the ACMG uniform panel (top: primary targets; center: secondary targets; and bottom: other conditions ${ }^{1}$ ). The darker bar color and the higher section of the $Y$-axis scale reflect the project goal to collect at least 50 cases of each condition. A case is considered eligible for submission if the following conditions have been met: (a) the diagnosis was confirmed by biochemical and in vitro testing according to local protocols; (b) results were from the first specimen only (no repeat samples); and (c) age at collection was between 1 and 7 days of life. A separate application in the newborn screening website domain has been activated to process the same types of data derived from routine second samples (project lead: Marzia Pasquali, PhD, University of Utah). Each case is assigned a unique code separate from any other traceable identifier, and no demographic information is collected except for the calendar year of birth. Accordingly, this project has been reviewed and approved as a minimum risk protocol by the Mayo Clinic Institutional Review Board (no. PR09-001709-01).

The average rate of submission of true positive cases between December 1, 2008, and December 1, 2010, was 5.1 cases/day $(3,651$ cases). The total number of true positive cases is approaching 11,000, and the range of number of cases per condition is 1-2,057, with a median of 47 . However, if only the primary targets of the ACMG panel were to be considered $(N=7,288)$, the range and median are $18-2,057$ and 210 , respectively. All primary conditions have exceeded 50 cases except 3-hydroxy 3-methylglutaryl-CoA lyase deficiency (OMIM number $300438 ; N=35$ ), $\beta$-ketothiolase deficiency (BKT, 203750; $N=26$ ), and multiple carboxylase deficiency (MCD, 253270; $N=18$ ). As of December 1, 2010, a total of 562,609 results (analyte values

\section{Phe}

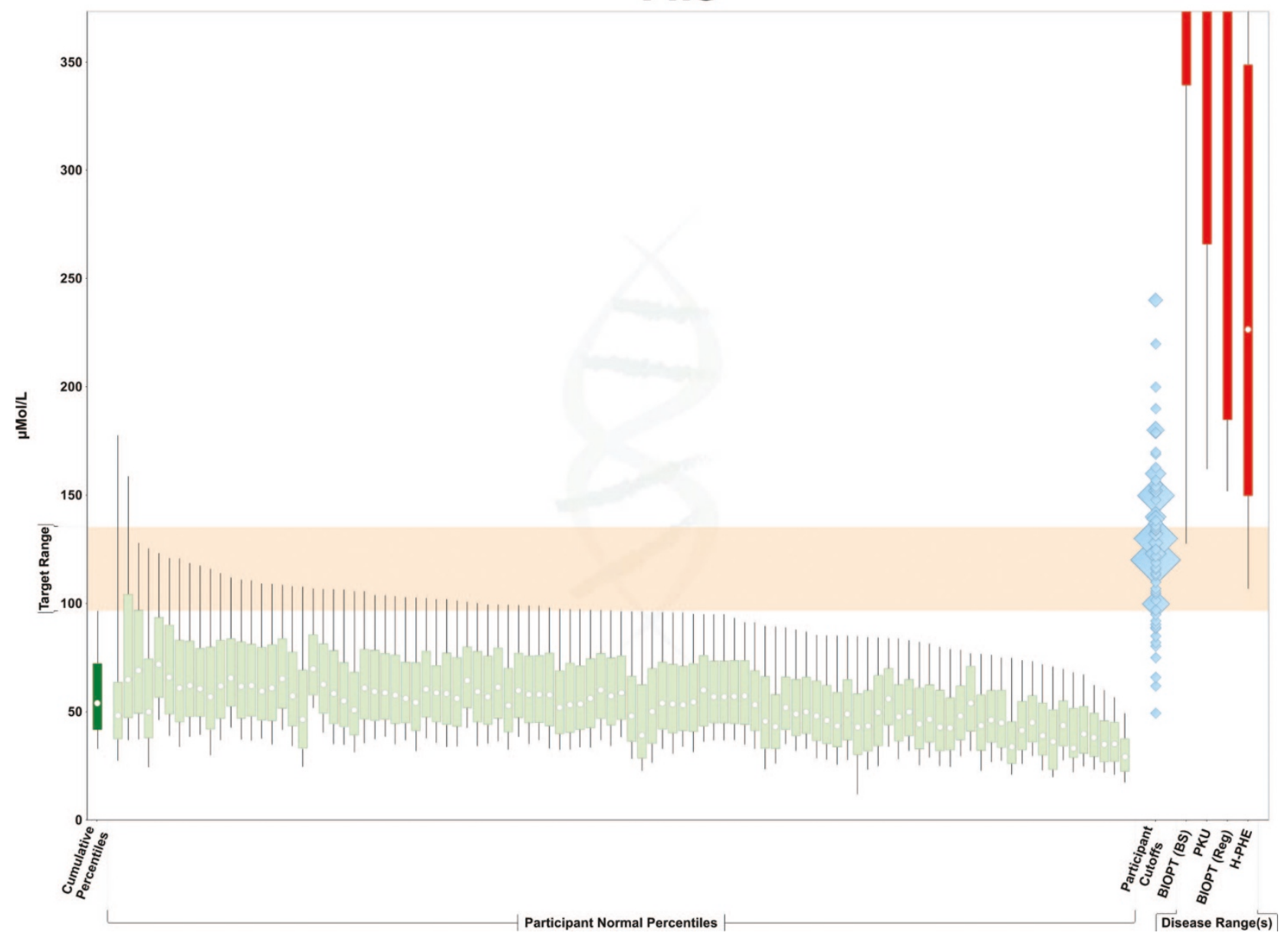

Fig. 3. R4S analyte comparison tool for the amino acid phenylalanine in neonatal dried blood spots. Each box represents the interval between the 10\%ile and $90 \%$ ile, the upper and lower lines extend to the $99 \%$ ile and $1 \%$ ile, respectively. The median is shown as a white circle in the body of the box. Color coding: dark green: cumulative percentiles; light green: percentiles of individual participants, sorted in descending order of the $99 \%$ ile value; orange: cutoff target range (see text for details); light blue diamonds: actual cutoff values of participants; the marker size is proportional to the number of laboratories using the same value; and bright red bars: disorder ranges (partially hidden by $Y$-axis reduction to allow the normal percentiles to be visible). For the number of cases included in each disorder range, see Table 2. Abbreviations are listed in the legend of Figure 2. 
and calculated ratios) have been submitted by 113 sites; $85 \%$ of the active participants have posted at least one new case since January 1, 2010. Not surprisingly, the number of cases submitted by individual sites varies considerably, ranging from 1 to 870, with an average of 130 .

\section{RESULTS}

The main deliverable of the R4S collaborative project is the definition of evidence-based cutoff target ranges for all analytes detected by MS/MS and related ratios. The cutoff target range could be either above (high) or below (low) the normal population: the high target range is defined as the interval between the cumulative 99th percentile of the normal population and the lowest 5 th percentile of all disorder ranges of the same marker (if the analyte is informative for multiple conditions). On the other hand, the low target range is defined as the interval between the highest 99th percentile of disorder ranges and the 1 st percentile of the normal population.
Table 1 presents the 1 st percentile, 50th percentile (median), and 99th percentile cumulative values of amino acid and acylcarnitine species. In response to the recent introduction of a modified commercial $\mathrm{kit}^{17}$ that does not include derivatization to butyl esters ${ }^{18}$ (used by $31 \%$ of R4S participants), the different overlaps of isobaric acylcarnitine species with and without derivatization (shown as [D] and [U], respectively; the two analytes are combined by the symbol "\&") are shown separately. For each percentile value, the coefficient of variation (calculated as standard deviation/mean) is also shown. Despite existing differences in preanalytical and analytical variables, including collection age, ${ }^{19}$ and the inconsistent use and reporting of decimal digits at the submicromolar level, overall variability of the median values was on average $23 \%$ for amino acids (Fig. 3, analyte comparison tool for the amino acid phenylalanine; see figure legend for details) and $27 \%$ for acylcarnitines. Similar results were observed for all calculated amino acid and acylcarnitine ratios (data not shown; available on request). Notable exceptions that showed greater variability

\section{BKT}

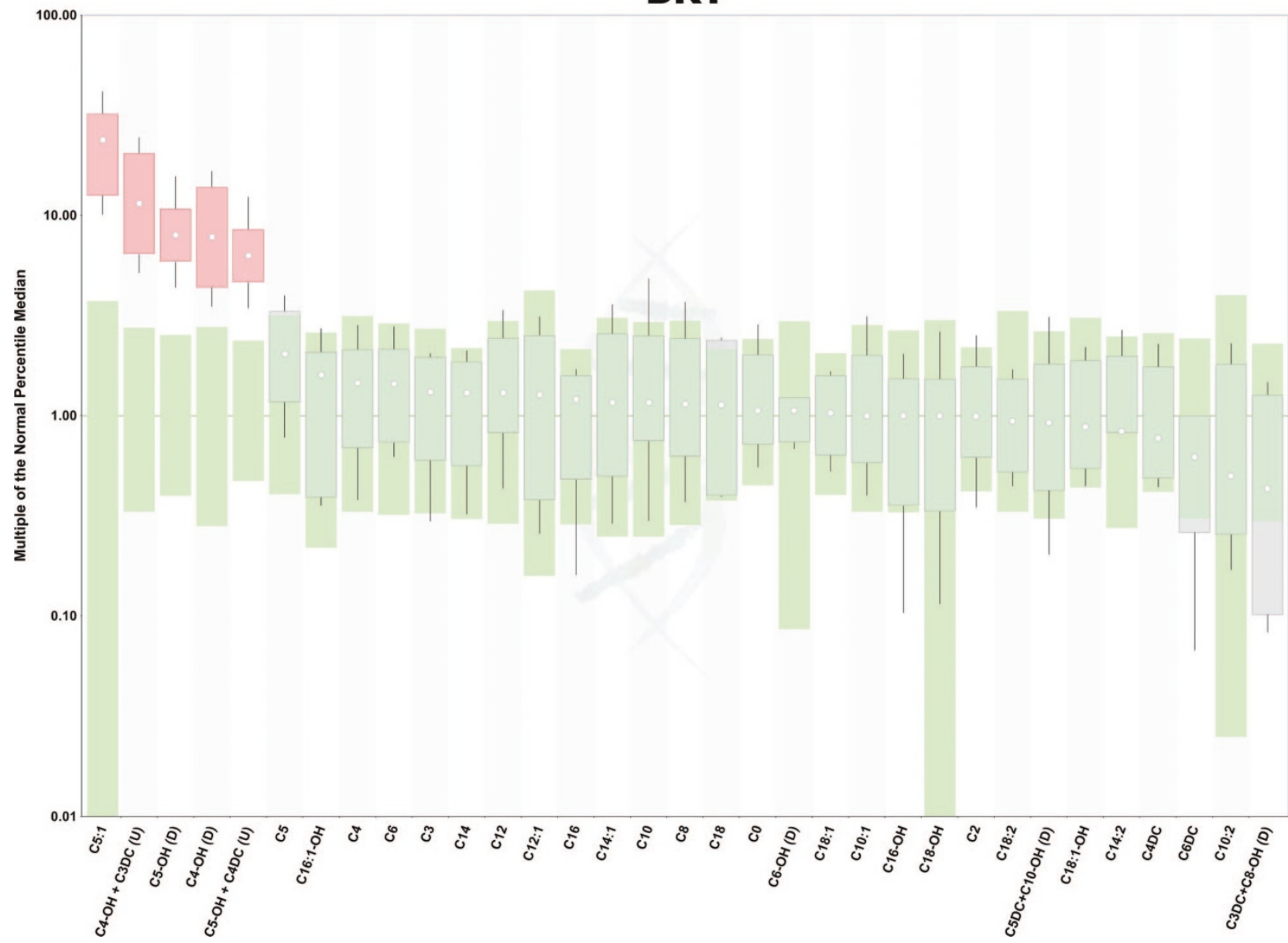

Fig. 4. R4S plot by condition for $\beta$-ketothiolase (BKT) deficiency. This plot converts each case value to the corresponding multiple of the cumulative median (MoM). Each box represents the interval between the 10\%ile and $90 \%$ ile, the upper and lower lines extend to the $99 \%$ ile and $1 \%$ ile, respectively. The median is shown as a white circle in the body of the box. Color coding: red: disorder ranges of informative markers; gray: disorder range of uninformative markers; and green: range of normal population. For the number of cases for informative analytes, see Table 4 . Abbreviations are listed in the legend of Figure 2. 
were argininosuccinic acid (Asa) and succinylacetone (Suac). The former showed significant differences between sites, with approximately half of the participants reporting normal values at a level much higher than seen in plasma, where Asa is usually undetectable. ${ }^{20}$ The remaining sites reported normal percentiles comparable with concentrations seen in plasma of normal newborns. Such a difference is unlikely to be explained solely by the analysis of a different specimen, neonatal dried blood spots, hence there seems to be some analytical factor behind these observations other than reagents and derivatization mode. There were no obvious differences based on the R4S participant profile compar- ison tool (data not shown), which is not fully informative because of the relatively small number of participants who are actively monitoring this analyte $(N=26)$. Suac is a relatively recent addition, also with limited participation $(N=22)$, and is measured using a variety of methods. ${ }^{21-24}$ It has been suggested that the observed variability could be improved by standardization of preanalytical variables. ${ }^{25,26}$ Despite these issues, both Asa and Suac are absolutely required for the reliable detection of two primary targets of the uniform panel, argininosuccinic acidemia (OMIM number 207900), and tyrosinemia type I (276700). Every effort should be made to expand their utilization and to mitigate existing differences among laboratories.

Table 2 Amino acid disorder ranges in neonatal dried blood spots analyzed by tandem mass spectrometry by participants of the Region 4 Stork collaborative project (as of December 1, 2010)

\begin{tabular}{|c|c|c|c|c|c|c|c|c|c|c|}
\hline \multirow{2}{*}{$\begin{array}{l}\text { Amino acids } \\
\text { Marker }\end{array}$} & \multirow[b]{2}{*}{ Condition } & \multirow[b]{2}{*}{$N$} & \multicolumn{8}{|c|}{ Percentiles of disorder ranges $(\mu \mathrm{mol} / \mathrm{L})$} \\
\hline & & & $1 \%$ & $5 \%$ & $10 \%$ & $25 \%$ & $50 \%$ & $75 \%$ & $90 \%$ & $99 \%$ \\
\hline $\operatorname{Arg}($ low) & OTC/CPS & 46 & 1.3 & 2.8 & 3.1 & 4.8 & 8.1 & 11 & 19 & 41 \\
\hline Arg & ARG & 22 & 35 & 51 & 72 & 95 & 138 & 209 & 286 & 336 \\
\hline Asa & ASA & 51 & 0.12 & 0.25 & 0.42 & 1.5 & 3.8 & 12 & 61 & 110 \\
\hline Cit (low) & OTC/CPS & 60 & 1.0 & 1.3 & 1.8 & 2.3 & 3.0 & 4.8 & 6.5 & 17 \\
\hline \multirow[t]{5}{*}{ Cit } & CIT-I & 215 & 54 & 72 & 102 & 172 & 366 & 745 & 1107 & 2213 \\
\hline & $\mathrm{PC}$ & 2 & 90 & 100 & 112 & 148 & 208 & 269 & 305 & 327 \\
\hline & CIT-II & 58 & 10 & 15 & 28 & 48 & 100 & 193 & 346 & 1047 \\
\hline & ASA & 108 & 22 & 32 & 40 & 65 & 95 & 141 & 177 & 342 \\
\hline & CIT-I (mat) & 2 & 41 & 44 & 49 & 62 & 84 & 105 & 119 & 126 \\
\hline Gln & OTC/CPS & 28 & 34 & 43 & 47 & 62 & 81 & 150 & 264 & 426 \\
\hline Glu & OTC/CPS & 31 & 153 & 183 & 205 & 227 & 308 & 393 & 519 & 818 \\
\hline Gly & NKHG & 44 & 113 & 435 & 539 & 656 & 940 & 1203 & 1360 & 1663 \\
\hline \multirow[t]{3}{*}{ Met (low) } & $\mathrm{Cbl} \mathrm{E}$ & 1 & 9.8 & 9.8 & 9.8 & 9.8 & 9.8 & 9.8 & 9.8 & 9.8 \\
\hline & $\mathrm{Cbl} \mathrm{G}$ & 3 & 4.8 & 5.0 & 5.4 & 6.4 & 8.1 & 8.9 & 9.4 & 9.7 \\
\hline & MTHFR & 4 & 4.2 & 4.3 & 4.4 & 4.7 & 5.4 & 6.4 & 7.3 & 7.9 \\
\hline \multirow[t]{2}{*}{ Met } & $\mathrm{HCY}$ & 89 & 31 & 48 & 55 & 67 & 106 & 188 & 474 & 900 \\
\hline & MET & 91 & 45 & 49 & 57 & 77 & 103 & 126 & 146 & 364 \\
\hline \multirow[t]{4}{*}{ Phe } & BIOPT (BS) & 46 & 128 & 292 & 340 & 391 & 726 & 1342 & 2131 & 3281 \\
\hline & PKU & 1922 & 162 & 233 & 267 & 342 & 480 & 707 & 971 & 1805 \\
\hline & BIOPT (Reg) & 16 & 152 & 156 & 185 & 265 & 478 & 938 & 1504 & 1967 \\
\hline & H-PHE & 1124 & 107 & 135 & 150 & 180 & 227 & 285 & 349 & 549 \\
\hline Suac & TYR-I & 59 & 3.8 & 8.8 & 13 & 20 & 35 & 47 & 66 & 148 \\
\hline \multirow[t]{4}{*}{ Tyr } & TYR-III & 1 & 907 & 907 & 907 & 907 & 907 & 907 & 907 & 907 \\
\hline & TYR (trans) & 71 & 160 & 219 & 301 & 444 & 563 & 777 & 876 & 1110 \\
\hline & TYR-II & 45 & 186 & 226 & 260 & 448 & 546 & 852 & 1105 & 1297 \\
\hline & TYR-I & 86 & 66 & 89 & 111 & 141 & 201 & 302 & 489 & 834 \\
\hline Val & MSUD & 199 & 57 & 168 & 218 & 290 & 359 & 493 & 647 & 1080 \\
\hline Xle & MSUD & 236 & 68 & 260 & 325 & 453 & 740 & 1429 & 2573 & 4313 \\
\hline
\end{tabular}

For abbreviations of analytes and conditions, see legends of Table 1 and Figure 2, respectively. Amino acids are listed in alphabetical order. When multiple conditions are shown, they are sorted in descending order of the median value of the disorder range. $N$, number of cases. 
Table 3 Disorder ranges of amino acid ratios in neonatal dried blood spots analyzed by tandem mass spectrometry by participants of the Region 4 Stork collaborative project (as of December 1, 2010)

\begin{tabular}{|c|c|c|c|c|c|c|c|c|c|c|}
\hline \multirow{2}{*}{$\begin{array}{l}\text { Amino acids } \\
\text { Marker }\end{array}$} & \multirow[b]{2}{*}{ Condition } & \multirow[b]{2}{*}{$N$} & \multicolumn{8}{|c|}{ Percentiles of disorder ranges } \\
\hline & & & $1 \%$ & $5 \%$ & $10 \%$ & $25 \%$ & $50 \%$ & $75 \%$ & $90 \%$ & $99 \%$ \\
\hline Arg/Ala & ARG & 14 & 0.10 & 0.15 & 0.18 & 0.30 & 0.57 & 0.75 & 1.0 & 1.5 \\
\hline Arg/Phe & ARG & 17 & 0.58 & 0.75 & 0.97 & 1.7 & 2.3 & 3.8 & 4.3 & 6.1 \\
\hline Asa/Arg & ASA & 44 & 0.008 & 0.027 & 0.034 & 0.19 & 0.81 & 1.9 & 3.8 & 28 \\
\hline \multirow[t]{2}{*}{ Cit/Arg (low) } & OTC/CPS & 46 & 0.066 & 0.11 & 0.20 & 0.25 & 0.36 & 0.59 & 0.92 & 2.6 \\
\hline & $\mathrm{ARG}$ & 17 & 0.058 & 0.068 & 0.074 & 0.082 & 0.12 & 0.22 & 0.28 & 0.29 \\
\hline \multirow[t]{5}{*}{ Cit/Arg } & CIT-I & 118 & 2.3 & 4.2 & 6.8 & 14 & 34 & 67 & 120 & 518 \\
\hline & $\mathrm{PC}$ & 2 & 18 & 18 & 18 & 20 & 21 & 23 & 25 & 25 \\
\hline & ASA & 81 & 1.5 & 2.8 & 3.2 & 6.1 & 9.7 & 16 & 27 & 49 \\
\hline & CIT-I (mat) & 1 & 8.0 & 8.0 & 8.0 & 8.0 & 8.0 & 8.0 & 8.0 & 8.0 \\
\hline & CIT-II & 53 & 0.73 & 1.1 & 1.6 & 3.0 & 6.0 & 12 & 20 & 42 \\
\hline Cit/Phe (low) & OTC/CPS & 60 & 0.013 & 0.027 & 0.033 & 0.041 & 0.054 & 0.090 & 0.15 & 0.44 \\
\hline \multirow[t]{5}{*}{$\mathrm{Cit} / \mathrm{Phe}$} & CIT-I & 159 & 0.48 & 0.98 & 1.8 & 2.9 & 5.6 & 13 & 19 & 44 \\
\hline & ASA & 88 & 0.40 & 0.48 & 0.70 & 1.1 & 1.7 & 2.9 & 4.2 & 7.1 \\
\hline & $\mathrm{PC}$ & 2 & 1.3 & 1.3 & 1.4 & 1.5 & 1.6 & 1.8 & 1.9 & 2.0 \\
\hline & CIT-II & 57 & 0.24 & 0.33 & 0.61 & 0.84 & 1.4 & 2.3 & 6.6 & 13 \\
\hline & CIT-I (mat) & 2 & 1.0 & 1.0 & 1.1 & 1.1 & 1.3 & 1.4 & 1.5 & 1.5 \\
\hline Gln/Cit (low) & CIT-I & 5 & 0.022 & 0.029 & 0.038 & 0.064 & 0.16 & 0.28 & 1.0 & 1.4 \\
\hline $\mathrm{Gln} / \mathrm{Cit}$ & OTC/CPS & 28 & 12 & 13 & 15 & 20 & 30 & 55 & 72 & 104 \\
\hline \multirow[t]{2}{*}{ Glu/Cit (low) } & CIT-II & 10 & 0.7 & 1.1 & 1.6 & 2.0 & 2.6 & 19 & 26 & 28 \\
\hline & CIT-I & 34 & 0.16 & 0.21 & 0.25 & 0.33 & 0.58 & 1.0 & 1.4 & 3.6 \\
\hline $\mathrm{Glu} / \mathrm{Cit}$ & OTC/CPS & 31 & 38 & 54 & 58 & 80 & 105 & 155 & 261 & 284 \\
\hline \multirow[t]{4}{*}{ Met/Cit (low) } & $\mathrm{Cbl} \mathrm{E}$ & 1 & 0.89 & 0.89 & 0.89 & 0.89 & 0.89 & 0.89 & 0.89 & 0.89 \\
\hline & $\mathrm{Cbl} \mathrm{G}$ & 3 & 0.59 & 0.60 & 0.62 & 0.66 & 0.75 & 0.91 & 1.0 & 1.1 \\
\hline & Cbl D v1 & 1 & 0.64 & 0.64 & 0.64 & 0.64 & 0.64 & 0.64 & 0.64 & 0.64 \\
\hline & MTHFR & 4 & 0.41 & 0.41 & 0.43 & 0.46 & 0.49 & 0.60 & 0.79 & 0.91 \\
\hline \multirow[t]{3}{*}{ Met/Cit } & OTC/CPS & 60 & 1.7 & 2.5 & 3.9 & 7.0 & 11 & 23 & 41 & 110 \\
\hline & $\mathrm{HCY}$ & 64 & 1.6 & 2.9 & 3.7 & 6.0 & 8.5 & 14 & 27 & 49 \\
\hline & MET & 84 & 2.9 & 3.7 & 4.0 & 5.5 & 7.7 & 10 & 15 & 22 \\
\hline \multirow[t]{3}{*}{ Met/Phe (low) } & $\mathrm{Cbl} \mathrm{E}$ & 1 & 0.17 & 0.17 & 0.17 & 0.17 & 0.17 & 0.17 & 0.17 & 0.17 \\
\hline & $\mathrm{Cbl} \mathrm{G}$ & 3 & 0.10 & 0.11 & 0.11 & 0.12 & 0.14 & 0.15 & 0.15 & 0.16 \\
\hline & MTHFR & 4 & 0.095 & 0.096 & 0.097 & 0.10 & 0.11 & 0.12 & 0.14 & 0.15 \\
\hline \multirow[t]{2}{*}{ Met/Phe } & $\mathrm{HCY}$ & 74 & 0.75 & 1.0 & 1.1 & 1.4 & 2.2 & 3.4 & 7.2 & 26 \\
\hline & MET & 85 & 0.79 & 0.98 & 1.1 & 1.4 & 1.8 & 2.4 & 3.2 & 5.4 \\
\hline \multirow[t]{4}{*}{ Met/Tyr (low) } & $\mathrm{Cbl} \mathrm{E}$ & 1 & 0.11 & 0.11 & 0.11 & 0.11 & 0.11 & 0.11 & 0.11 & 0.11 \\
\hline & $\mathrm{Cbl} \mathrm{G}$ & 3 & 0.067 & 0.070 & 0.074 & 0.085 & 0.10 & 0.10 & 0.11 & 0.11 \\
\hline & MTHFR & 4 & 0.045 & 0.049 & 0.054 & 0.068 & 0.076 & 0.091 & 0.12 & 0.13 \\
\hline & Cbl D v1 & 1 & 0.048 & 0.048 & 0.048 & 0.048 & 0.048 & 0.048 & 0.048 & 0.048 \\
\hline
\end{tabular}


Table 3 Continued

\begin{tabular}{|c|c|c|c|c|c|c|c|c|c|c|}
\hline \multirow{2}{*}{$\begin{array}{l}\text { Amino acids } \\
\text { Marker }\end{array}$} & \multirow[b]{2}{*}{ Condition } & \multirow[b]{2}{*}{$N$} & \multicolumn{8}{|c|}{ Percentiles of disorder ranges } \\
\hline & & & $1 \%$ & $5 \%$ & $10 \%$ & $25 \%$ & $50 \%$ & $75 \%$ & $90 \%$ & $99 \%$ \\
\hline \multirow[t]{2}{*}{ Met/Tyr } & $\mathrm{HCY}$ & 67 & 0.38 & 0.63 & 0.68 & 0.87 & 1.2 & 2.0 & 3.7 & 9.3 \\
\hline & MET & 84 & 0.28 & 0.47 & 0.57 & 0.79 & 1.1 & 1.7 & 2.2 & 3.7 \\
\hline \multirow[t]{4}{*}{ Met/Xle (low) } & $\mathrm{Cbl} \mathrm{E}$ & 1 & 0.10 & 0.10 & 0.10 & 0.10 & 0.10 & 0.10 & 0.10 & 0.10 \\
\hline & MTHFR & 4 & 0.043 & 0.046 & 0.049 & 0.058 & 0.067 & 0.073 & 0.077 & 0.080 \\
\hline & $\mathrm{Cbl} \mathrm{G}$ & 3 & 0.038 & 0.039 & 0.041 & 0.047 & 0.057 & 0.10 & 0.13 & 0.15 \\
\hline & Cbl D v1 & 1 & 0.046 & 0.046 & 0.046 & 0.046 & 0.046 & 0.046 & 0.046 & 0.046 \\
\hline \multirow[t]{2}{*}{ Met/Xle } & $\mathrm{HCY}$ & 64 & 0.20 & 0.32 & 0.44 & 0.62 & 0.92 & 1.2 & 2.3 & 6.9 \\
\hline & MET & 80 & 0.28 & 0.32 & 0.38 & 0.48 & 0.66 & 0.91 & 1.3 & 3.0 \\
\hline \multirow[t]{4}{*}{ Phe/Tyr } & PKU & 1779 & 2.1 & 3.4 & 4.3 & 6.4 & 9.4 & 14 & 19 & 46 \\
\hline & BIOPT (Reg) & 5 & 1.8 & 2.4 & 3.0 & 5.0 & 5.7 & 9.1 & 9.2 & 9.3 \\
\hline & BIOPT (BS) & 8 & 1.3 & 1.6 & 2.0 & 3.1 & 5.0 & 8.2 & 15 & 18 \\
\hline & H-PHE & 1034 & 1.1 & 1.5 & 1.8 & 2.4 & 3.3 & 4.5 & 6.3 & 11 \\
\hline $\mathrm{Val} / \mathrm{Phe}$ & MSUD & 172 & 1.1 & 2.3 & 3.4 & 5.3 & 7.5 & 9.8 & 13 & 23 \\
\hline Xle/Ala & MSUD & 145 & 0.35 & 0.73 & 1.1 & 2.7 & 5.3 & 10 & 25 & 42 \\
\hline $\mathrm{Xle} / \mathrm{Phe}$ & MSUD & 193 & 1.4 & 3.8 & 5.4 & 9.3 & 15 & 27 & 55 & 76 \\
\hline
\end{tabular}

For abbreviations of analytes and conditions, see legends of Table 1 and Figure 2, respectively. Amino acid ratios are listed in alphabetical order. When multiple conditions are shown, they are sorted by descending order (highest first) of the median value of the disorder range.

The second defining element of the target range is calculated from the disorder ranges of all conditions related to a specific marker or ratio. The attribution of a marker to a condition stems from an objective process applied to establish a threshold of clinical utility. In the R4S project, clinical significance is attributed to a marker-to-condition association when at least half of the true positive cases with a given condition have values outside the normal population, defined as the interval between the average $1 \%$ and $99 \%$ percentiles calculated from the data submitted by all participating sites. An example of the above process is shown in Figure 4, the plot by condition for BKT. This R4S plot shows, on a log scale, a comparison between normal and disorder ranges after conversion of all quantitative values to the corresponding multiple of the average median. BKT was chosen as an example in this study because the R4S plots were instrumental for the initial recognition that hydroxy butyrylcarnitine $(\mathrm{C} 4-\mathrm{OH})$ is a highly informative marker of this condition, one that moving forward should not be overlooked in the complex differential diagnosis of an elevated concentration of hydroxy isovalerylcarnitine $(\mathrm{C} 5-\mathrm{OH}){ }^{27}$

Based on the results of 10,679 true positive cases, the disorder ranges of amino acids, amino acid ratios, acylcarnitines, and acylcarnitine ratios are listed in Tables $2-5$, respectively. The suffix "(low)" attached to a marker indicates clinical significance below the normal population, triggering the selection of a low cutoff value. A need for a low threshold was documented for all types of analytes: amino acids (3), amino acid ratios (7), acylcarnitines (7), and acylcarnitine ratios (6), underscoring how underused they currently are. The disorder ranges for a given analyte are conditionspecific and listed together to facilitate comparative analysis. Rows are sorted in a descending order based on the median value; the number of cases for each condition is also provided. Differences between analyte counts related to the same condition reflect the variability of past and current testing panels of the participants. For example, 107 participants have a cutoff for octanoylcarnitine (C8), but only 87 of them also monitor decenoylcarnitine (C10:1). However, these differences have declined substantially since the beginning of the collaborative project.

All data shown earlier in the text are combined to achieve the primary objective of this project, which is the definition of clinically relevant cutoff target ranges. Table 6 presents all markers with a low cutoff target range. In addition to the number of cases, and how many conditions could be detected, it introduces the key concept of "override." One or both limits of a target range may need to be adjusted in response to the degree of overlap between normal population and disorder range. The ideal situation (no override at either end) occurs in $35 \%$ of all markers combined (40/114), amino acids $32 \%$, and acylcarnitines 38\%. The opposite scenario (need to override at both ends because of pervasive overlap) was encountered in $25 \%$ of the markers. The intermediate situation (partial overlap at either limit) is frequent (40\%) and reflects the variability of the biochemical phenotype of these disorders in asymptomatic newborns and underscores the importance of using an evidence-based rather than statistical approach to the selection of a cutoff value. Tables 7 and 8 present the high cutoff target ranges for amino acids and acylcarnitines, respectively. The only difference is found in the reliance on the lowest 5 th percentile of all disorder ranges for a given analyte. The choice of a slightly higher limit is driven by the recognition that false negative cases have been encountered in virtually all conditions. ${ }^{28-30}$ Once the possibility of a cutoff value set too high has been considered, ${ }^{31}$ it must be recognized that a small number of cases could just be undetectable on the sole basis of their biochemical phenotype. Although this is unfortunate, the quest for perfect sensitivity should not be a reason to artificially set cutoff values so close to the 
Table 4 Acylcarnitine disorder ranges in neonatal dried blood spots analyzed by tandem mass spectrometry by participants of the Region 4 Stork collaborative project (as of December 1, 2010)

\begin{tabular}{|c|c|c|c|c|c|c|c|c|c|c|}
\hline \multirow[b]{2}{*}{ Marker } & \multirow[b]{2}{*}{ Condition } & \multirow[b]{2}{*}{$N$} & \multicolumn{8}{|c|}{ Percentiles of disorder ranges } \\
\hline & & & $1 \%$ & $5 \%$ & $10 \%$ & $25 \%$ & $50 \%$ & $75 \%$ & $90 \%$ & $99 \%$ \\
\hline \multirow[t]{5}{*}{ C0 (low) } & 3MCC (mat) & 95 & 3.8 & 5.0 & 5.4 & 7.8 & 14 & 23 & 34 & 59 \\
\hline & MCAD (mat) & 3 & 5.2 & 5.3 & 5.6 & 6.3 & 7.4 & 9.2 & 10 & 11 \\
\hline & CUD & 193 & 1.9 & 2.6 & 3.1 & 4.4 & 6.2 & 8.7 & 11 & 17 \\
\hline & CUD (mat) & 86 & 0.53 & 2.3 & 2.5 & 3.7 & 5.1 & 6.8 & 8.3 & 11 \\
\hline & GA-I (mat) & 4 & 3.4 & 3.5 & 3.6 & 3.8 & 4.4 & 5.5 & 6.8 & 7.6 \\
\hline \multirow[t]{2}{*}{$\mathrm{C} 0$} & CPT-I & 56 & 37 & 42 & 57 & 93 & 118 & 140 & 166 & 360 \\
\hline & CPT-1 (P479L) & 11 & 28 & 38 & 51 & 60 & 76 & 81 & 99 & 113 \\
\hline \multirow[t]{4}{*}{ C2 (low) } & CUD & 179 & 2.9 & 4.0 & 5.1 & 6.9 & 10 & 14 & 19 & 30 \\
\hline & CUD (mat) & 69 & 2.7 & 5.4 & 5.7 & 6.8 & 9.8 & 13 & 15 & 22 \\
\hline & CPT-II & 35 & 1.0 & 1.4 & 2.4 & 5.4 & 8.0 & 16 & 32 & 54 \\
\hline & MCAD (mat) & 3 & 3.3 & 3.6 & 3.9 & 4.9 & 6.5 & 7.3 & 7.8 & 8.1 \\
\hline \multirow[t]{2}{*}{ C3 (low) } & CUD (mat) & 71 & 0.18 & 0.23 & 0.26 & 0.33 & 0.54 & 0.70 & 0.88 & 1.7 \\
\hline & CUD & 173 & 0.079 & 0.13 & 0.20 & 0.30 & 0.45 & 0.62 & 0.90 & 1.3 \\
\hline \multirow[t]{5}{*}{$\mathrm{C} 3$} & PROP & 201 & 2.3 & 5.5 & 6.3 & 8.9 & 14 & 19 & 24 & 51 \\
\hline & MUT/Cbl A,B & 328 & 1.1 & 3.5 & 4.8 & 7.1 & 9.5 & 14 & 18 & 40 \\
\hline & Cbl C,D & 124 & 2.8 & 3.6 & 4.5 & 6.2 & 8.4 & 10 & 13 & 20 \\
\hline & B12 def (mat) & 47 & 2.55 & 3.0 & 4.0 & 5.9 & 7.8 & 9.0 & 15 & 22 \\
\hline & $\mathrm{MCD}$ & 15 & 1.6 & 1.6 & 1.7 & 2.3 & 4.6 & 6.5 & 14 & 16 \\
\hline \multirow[t]{5}{*}{$\mathrm{C} 4$} & SCAD & 572 & 1.0 & 1.3 & 1.4 & 1.7 & 2.0 & 2.4 & 3.0 & 4.8 \\
\hline & $\mathrm{EE}$ & 8 & 1.2 & 1.2 & 1.3 & 1.4 & 2.0 & 2.3 & 2.7 & 2.7 \\
\hline & IBG & 82 & 0.88 & 1.1 & 1.2 & 1.6 & 2.0 & 2.4 & 2.8 & 3.8 \\
\hline & FIGLU & 26 & 0.79 & 1.0 & 1.1 & 1.6 & 1.7 & 2.4 & 3.2 & 5.5 \\
\hline & GA-II & 99 & 0.19 & 0.41 & 0.50 & 0.79 & 1.7 & 2.6 & 4.4 & 6.9 \\
\hline \multirow[t]{2}{*}{ C5:1 } & 2M3HBA & 1 & 0.63 & 0.63 & 0.63 & 0.63 & 0.63 & 0.63 & 0.63 & 0.63 \\
\hline & BKT & 23 & 0.22 & 0.24 & 0.27 & 0.37 & 0.51 & 0.58 & 0.69 & 0.89 \\
\hline \multirow[t]{4}{*}{$\mathrm{C} 5$} & IVA & 216 & 0.58 & 1.2 & 1.5 & 2.2 & 3.8 & 8.8 & 12 & 19 \\
\hline & GA-II & 95 & 0.091 & 0.16 & 0.18 & 0.36 & 0.97 & 2.2 & 4.8 & 8.7 \\
\hline & $2 \mathrm{MBG}$ & 210 & 0.44 & 0.47 & 0.52 & 0.60 & 0.71 & 0.92 & 1.2 & 2.7 \\
\hline & $\mathrm{EE}$ & 6 & 0.010 & 0.017 & 0.026 & 0.12 & 0.38 & 0.66 & 0.81 & 0.87 \\
\hline \multirow[t]{2}{*}{$\mathrm{C} 4-\mathrm{OH}$} & BKT & 11 & 0.62 & 0.69 & 0.77 & 1.2 & 1.4 & 1.9 & 2.5 & 2.9 \\
\hline & M/SCHAD & 3 & 0.73 & 0.77 & 0.82 & 0.97 & 1.2 & 1.6 & 1.9 & 2.0 \\
\hline \multirow[t]{3}{*}{ C6 } & MCAD & 1690 & 0.13 & 0.24 & 0.32 & 0.62 & 1.1 & 1.9 & 2.7 & 4.6 \\
\hline & GA-II & 91 & 0.069 & 0.11 & 0.15 & 0.22 & 0.36 & 0.68 & 1.6 & 3.9 \\
\hline & MCAD (het) & 121 & 0.092 & 0.10 & 0.12 & 0.16 & 0.19 & 0.23 & 0.33 & 0.71 \\
\hline
\end{tabular}


Table 4 Continued

\begin{tabular}{|c|c|c|c|c|c|c|c|c|c|c|}
\hline \multirow[b]{2}{*}{ Marker } & \multirow[b]{2}{*}{ Condition } & \multirow[b]{2}{*}{$N$} & \multicolumn{8}{|c|}{ Percentiles of disorder ranges } \\
\hline & & & $1 \%$ & $5 \%$ & $10 \%$ & $25 \%$ & $50 \%$ & $75 \%$ & $90 \%$ & $99 \%$ \\
\hline \multirow[t]{8}{*}{$\mathrm{C} 5-\mathrm{OH}$} & 3MCC (mat) & 129 & 0.90 & 1.1 & 1.4 & 3.0 & 5.8 & 9.6 & 13 & 37 \\
\hline & $3 \mathrm{MCC}$ & 597 & 0.64 & 0.81 & 1.0 & 1.4 & 3.3 & 6.8 & 11 & 20 \\
\hline & $\mathrm{HMG}$ & 34 & 0.26 & 0.69 & 1.1 & 1.4 & 2.0 & 3.3 & 4.6 & 7.6 \\
\hline & MCD & 14 & 0.79 & 0.85 & 0.97 & 1.3 & 1.8 & 2.5 & 3.0 & 9.3 \\
\hline & 3MGA & 18 & 0.72 & 0.74 & 0.79 & 1.1 & 1.7 & 2.2 & 2.8 & 3.7 \\
\hline & BIOT (P) & 10 & 0.20 & 0.53 & 0.96 & 1.3 & 1.5 & 1.1 & 1.9 & 2.9 \\
\hline & BKT & 25 & 0.66 & 0.73 & 0.89 & 0.95 & 1.2 & 1.4 & 1.6 & 2.4 \\
\hline & 2M3HBA & 1 & 1.1 & 1.1 & 1.1 & 1.1 & 1.1 & 1.1 & 1.1 & 1.1 \\
\hline $\mathrm{C} 6-\mathrm{OH}$ & $\mathrm{M} / \mathrm{SCHAD}$ & 1 & 0.12 & 0.12 & 0.12 & 0.12 & 0.12 & 0.12 & 0.12 & 0.12 \\
\hline \multirow[t]{4}{*}{$\mathrm{C} 8$} & MCAD & 2026 & 0.40 & 0.70 & 1.1 & 2.5 & 7.1 & 14 & 23 & 40 \\
\hline & GA-II & 101 & 0.050 & 0.090 & 0.12 & 0.31 & 0.63 & 1.2 & 2.4 & 6.3 \\
\hline & MCAD (het) & 137 & 0.19 & 0.22 & 0.24 & 0.31 & 0.42 & 0.57 & 0.79 & 3.3 \\
\hline & MCAD (mat) & 3 & 0.031 & 0.035 & 0.040 & 0.055 & 0.080 & 0.11 & 0.13 & 0.14 \\
\hline \multirow[t]{2}{*}{ C3-DC } & MAL & 25 & 0.40 & 0.44 & 0.51 & 0.80 & 1.5 & 2.7 & 3.9 & 6.2 \\
\hline & MCAD & 905 & 0.020 & 0.050 & 0.070 & 0.12 & 0.22 & 0.37 & 0.57 & 1.0 \\
\hline C10:2 & RED & 1 & 0.12 & 0.12 & 0.12 & 0.12 & 0.12 & 0.12 & 0.12 & 0.12 \\
\hline \multirow[t]{2}{*}{ C10:1 } & MCAD & 1612 & 0.070 & 0.15 & 0.20 & 0.32 & 0.51 & 0.76 & 1.0 & 1.9 \\
\hline & MCAD (het) & 123 & 0.070 & 0.074 & 0.085 & 0.11 & 0.14 & 0.18 & 0.24 & 0.44 \\
\hline \multirow[t]{3}{*}{$\mathrm{C} 10$} & GA-II & 94 & 0.038 & 0.11 & 0.18 & 0.48 & 0.92 & 1.6 & 2.6 & 5.9 \\
\hline & MCAD & 1796 & 0.080 & 0.15 & 0.24 & 0.47 & 0.83 & 1.3 & 2.0 & 3.6 \\
\hline & MCAD (het) & 137 & 0.21 & 0.25 & 0.27 & 0.38 & 0.55 & 0.72 & 0.94 & 1.3 \\
\hline \multirow[t]{3}{*}{ C5-DC } & GA-I & 273 & 0.12 & 0.21 & 0.35 & 0.54 & 1.2 & 2.1 & 3.7 & 6.6 \\
\hline & GA-II & 88 & 0.016 & 0.045 & 0.067 & 0.16 & 0.30 & 0.63 & 0.84 & 1.7 \\
\hline & MCAD & 1382 & 0.008 & 0.020 & 0.040 & 0.11 & 0.21 & 0.35 & 0.53 & 1.1 \\
\hline \multirow[t]{3}{*}{$\mathrm{C} 12: 1$} & GA-II & 53 & 0.020 & 0.030 & 0.054 & 0.16 & 0.44 & 0.80 & 1.4 & 2.9 \\
\hline & VLCAD (het) & 59 & 0.15 & 0.20 & 0.26 & 0.35 & 0.43 & 0.57 & 0.74 & 0.94 \\
\hline & VLCAD & 242 & 0.035 & 0.083 & 0.13 & 0.22 & 0.34 & 0.50 & 0.64 & 1.3 \\
\hline \multirow[t]{5}{*}{$\mathrm{C} 12$} & GA-II & 70 & 0.14 & 0.20 & 0.32 & 0.71 & 1.5 & 2.1 & 3.1 & 6.0 \\
\hline & CPT-II & 28 & 0.10 & 0.21 & 0.32 & 0.64 & 0.83 & 1.7 & 2.3 & 3.0 \\
\hline & CACT & 6 & 0.20 & 0.23 & 0.28 & 0.42 & 0.71 & 0.91 & 1.0 & 1.1 \\
\hline & VLCAD & 287 & 0.096 & 0.26 & 0.34 & 0.48 & 0.62 & 0.92 & 1.2 & 2.4 \\
\hline & VLCAD (het) & 68 & 0.28 & 0.33 & 0.37 & 0.48 & 0.58 & 0.73 & 0.85 & 1.4 \\
\hline C6-DC & HMG & 17 & 0.028 & 0.060 & 0.087 & 0.13 & 0.18 & 0.20 & 0.51 & 0.92 \\
\hline \multirow[t]{4}{*}{$\mathrm{C} 14: 2$} & VLCAD & 275 & 0.042 & 0.079 & 0.10 & 0.15 & 0.24 & 0.38 & 0.53 & 1.3 \\
\hline & GA-II & 44 & 0.037 & 0.051 & 0.070 & 0.10 & 0.17 & 0.25 & 0.35 & 0.44 \\
\hline & LCHAD/TFP & 109 & 0.021 & 0.054 & 0.064 & 0.10 & 0.15 & 0.23 & 0.32 & 1.6 \\
\hline & VLCAD (het) & 63 & 0.061 & 0.070 & 0.082 & 0.10 & 0.12 & 0.18 & 0.22 & 0.27 \\
\hline \multirow[t]{4}{*}{$\mathrm{C} 14: 1$} & VLCAD & 438 & 0.41 & 0.71 & 0.83 & 1.1 & 1.8 & 3.3 & 5.0 & 10 \\
\hline & GA-II & 91 & 0.11 & 0.17 & 0.20 & 0.49 & 1.1 & 1.7 & 2.7 & 4.2 \\
\hline & VLCAD (het) & 91 & 0.49 & 0.63 & 0.66 & 0.72 & 0.86 & 0.97 & 1.2 & 1.7 \\
\hline & LCHAD/TFP & 156 & 0.098 & 0.16 & 0.23 & 0.38 & 0.63 & 1.0 & 1.4 & 2.1 \\
\hline
\end{tabular}


Table 4 Continued

\begin{tabular}{|c|c|c|c|c|c|c|c|c|c|c|}
\hline \multirow[b]{2}{*}{ Marker } & \multirow[b]{2}{*}{ Condition } & \multirow[b]{2}{*}{$N$} & \multicolumn{8}{|c|}{ Percentiles of disorder ranges } \\
\hline & & & $1 \%$ & $5 \%$ & $10 \%$ & $25 \%$ & $50 \%$ & $75 \%$ & $90 \%$ & $99 \%$ \\
\hline \multirow[t]{6}{*}{$\mathrm{C} 14$} & GA-II & 93 & 0.14 & 0.25 & 0.36 & 0.76 & 1.6 & 2.3 & 3.6 & 7.0 \\
\hline & CPT-II & 37 & 0.24 & 0.33 & 0.44 & 0.85 & 1.4 & 2.1 & 3.0 & 4.3 \\
\hline & VLCAD & 403 & 0.24 & 0.50 & 0.62 & 0.83 & 1.3 & 2.5 & 4.1 & 7.4 \\
\hline & CACT & 10 & 0.66 & 0.67 & 0.68 & 0.78 & 1.2 & 1.5 & 1.7 & 3.1 \\
\hline & VLCAD (het) & 88 & 0.36 & 0.49 & 0.53 & 0.61 & 0.73 & 0.89 & 1.0 & 1.8 \\
\hline & LCHAD/TFP & 140 & 0.15 & 0.22 & 0.27 & 0.41 & 0.63 & 0.95 & 1.4 & 2.5 \\
\hline \multirow[t]{4}{*}{ C16 (low) } & CPT-I (P479L) & 11 & 0.30 & 0.30 & 0.30 & 0.70 & 1.1 & 1.6 & 2.4 & 3.1 \\
\hline & CUD (mat) & 71 & 0.30 & 0.45 & 0.50 & 0.76 & 0.99 & 1.3 & 1.5 & 2.0 \\
\hline & CUD & 176 & 0.15 & 0.23 & 0.40 & 0.64 & 0.88 & 1.2 & 1.5 & 2.4 \\
\hline & CPT-I & 54 & 0.14 & 0.16 & 0.20 & 0.37 & 0.73 & 1.3 & 1.7 & 2.8 \\
\hline \multirow[t]{2}{*}{ C16 } & CACT & 15 & 6.0 & 6.8 & 7.5 & 11 & 18 & 21 & 24 & 31 \\
\hline & CPT-II & 47 & 4.0 & 7.1 & 7.7 & 9.9 & 15 & 23 & 32 & 44 \\
\hline \multirow[t]{2}{*}{ C18:2 (low) } & CPT-I (P479L) & 11 & 0.066 & 0.090 & 0.12 & 0.13 & 0.15 & 0.27 & 0.48 & 0.62 \\
\hline & CPT-I & 31 & 0.010 & 0.012 & 0.020 & 0.040 & 0.061 & 0.15 & 0.21 & 0.40 \\
\hline \multirow[t]{2}{*}{ C18:2 } & CPT-II & 23 & 0.12 & 0.20 & 0.43 & 0.54 & 0.75 & 2.4 & 3.1 & 5.4 \\
\hline & CACT & 5 & 0.28 & 0.31 & 0.34 & 0.43 & 0.46 & 0.53 & 0.64 & 0.70 \\
\hline \multirow[t]{5}{*}{ C18:1 (low) } & CPT-I (P479L) & 11 & 0.35 & 0.46 & 0.60 & 0.70 & 0.81 & 1.1 & 1.3 & 1.4 \\
\hline & CPT-I & 34 & 0.014 & 0.047 & 0.09 & 0.19 & 0.38 & 0.63 & 0.76 & 1.3 \\
\hline & CUD (mat) & 62 & 0.053 & 0.16 & 0.21 & 0.31 & 0.38 & 0.47 & 0.52 & 0.71 \\
\hline & CUD & 150 & 0.053 & 0.17 & 0.20 & 0.28 & 0.37 & 0.45 & 0.63 & 1.6 \\
\hline & GA-I (mat) & 2 & 0.29 & 0.29 & 0.29 & 0.30 & 0.31 & 0.31 & 0.32 & 0.32 \\
\hline \multirow[t]{2}{*}{ C18:1 } & CPT-II & 39 & 0.80 & 1.9 & 2.3 & 3.2 & 5.0 & 8.5 & 14 & 21 \\
\hline & CACT & 9 & 2.1 & 2.4 & 2.7 & 3.4 & 4.4 & 5.0 & 5.7 & 6.8 \\
\hline \multirow[t]{5}{*}{ C18 (low) } & CPT-I (P479L) & 11 & 0.25 & 0.26 & 0.27 & 0.32 & 0.45 & 0.63 & 0.70 & 0.83 \\
\hline & CPT-I & 54 & 0.035 & 0.047 & 0.09 & 0.16 & 0.29 & 0.42 & 0.54 & 0.89 \\
\hline & CUD & 129 & 0.051 & 0.11 & 0.14 & 0.20 & 0.27 & 0.37 & 0.49 & 0.94 \\
\hline & CUD (mat) & 56 & 0.067 & 0.11 & 0.14 & 0.18 & 0.25 & 0.32 & 0.40 & 0.49 \\
\hline & GA-I (mat) & 2 & 0.18 & 0.18 & 0.18 & 0.18 & 0.19 & 0.19 & 0.19 & 0.19 \\
\hline \multirow[t]{2}{*}{$\mathrm{C} 18$} & CPT-II & 34 & 0.84 & 1.0 & 1.8 & 2.5 & 3.6 & 6.1 & 8.9 & 10 \\
\hline & CACT & 10 & 1.2 & 1.3 & 1.4 & 2.2 & 3.1 & 3.3 & 4.0 & 5.5 \\
\hline \multirow[t]{3}{*}{ C16:1-OH } & PROP & 70 & 0.010 & 0.024 & 0.030 & 0.084 & 0.18 & 0.29 & 0.41 & 0.68 \\
\hline & LCHAD/TFP & 72 & 0.061 & 0.080 & 0.091 & 0.11 & 0.18 & 0.28 & 0.38 & 0.76 \\
\hline & MUT/Cbl A,B & 97 & 0.002 & 0.011 & 0.033 & 0.070 & 0.15 & 0.27 & 0.35 & 0.57 \\
\hline $\mathrm{C} 16-\mathrm{OH}$ & LCHAD/TFP & 168 & 0.074 & 0.19 & 0.27 & 0.39 & 0.71 & 1.3 & 2.0 & 4.1 \\
\hline C18:1-OH & LCHAD/TFP & 153 & 0.032 & 0.081 & 0.14 & 0.26 & 0.55 & 0.82 & 1.1 & 2.0 \\
\hline \multirow[t]{2}{*}{$\mathrm{C} 18-\mathrm{OH}$} & LCHAD/TFP & 113 & 0.032 & 0.069 & 0.15 & 0.34 & 0.57 & 0.93 & 1.3 & 2.7 \\
\hline & CACT & 5 & 0.022 & 0.028 & 0.036 & 0.060 & 0.080 & 0.11 & 0.11 & 0.11 \\
\hline
\end{tabular}

For abbreviations of analytes and conditions, see legends of Table 1 and Figure 2, respectively. Acylcarnitines are listed in increasing molecular weight order. When multiple conditions are shown, they are sorted by descending order (highest first) of the median values of the disorder range. 
Table 5 Disorder ranges of acylcarnitine ratios in neonatal dried blood spots analyzed by tandem mass spectrometry by participants of the Region 4 Stork collaborative project (as of December 1, 2010)

\begin{tabular}{|c|c|c|c|c|c|c|c|c|c|c|}
\hline \multirow[b]{2}{*}{ Marker } & \multirow[b]{2}{*}{ Condition } & \multirow[b]{2}{*}{$N$} & \multicolumn{8}{|c|}{ Percentiles of disorder ranges } \\
\hline & & & $1 \%$ & $5 \%$ & $10 \%$ & $25 \%$ & $50 \%$ & $75 \%$ & $90 \%$ & $99 \%$ \\
\hline \multirow[t]{2}{*}{ ACs/Cit (low) } & CUD (mat) & 50 & 0.70 & 0.79 & 0.94 & 1.3 & 1.6 & 2.0 & 2.6 & 3.5 \\
\hline & CUD & 116 & 0.51 & 0.77 & 0.94 & 1.2 & 1.6 & 2.2 & 3.3 & 4.5 \\
\hline $\mathrm{ACs} / \mathrm{Cit}$ & $\mathrm{OTC} / \mathrm{CPS}$ & 47 & 3.5 & 5.7 & 8.5 & 14 & 24 & 33 & 38 & 81 \\
\hline \multirow[t]{2}{*}{$\mathrm{C} 0 /(\mathrm{C} 16+\mathrm{C} 18)($ low $)$} & CPT-II & 30 & 0.31 & 0.31 & 0.40 & 0.53 & 1.0 & 2.0 & 4.1 & 8.4 \\
\hline & CACT & 9 & 0.17 & 0.19 & 0.21 & 0.23 & 0.85 & 1.1 & 2.0 & 4.6 \\
\hline \multirow[t]{2}{*}{$\mathrm{C} 0 /(\mathrm{C} 16+\mathrm{C} 18)$} & CPT-I & 54 & 21 & 41 & 49 & 72 & 105 & 182 & 311 & 774 \\
\hline & CPT-I (P479L) & 11 & 19 & 26 & 35 & 38 & 44 & 59 & 77 & 91 \\
\hline \multirow[t]{5}{*}{$\mathrm{C} 3 / \mathrm{C} 2$} & PROP & 184 & 0.10 & 0.24 & 0.31 & 0.47 & 0.78 & 1.4 & 1.7 & 3.5 \\
\hline & MUT/Cbl A,B & 303 & 0.055 & 0.16 & 0.21 & 0.30 & 0.45 & 0.62 & 0.90 & 3.1 \\
\hline & Cbl C,D & 118 & 0.12 & 0.18 & 0.21 & 0.27 & 0.38 & 0.50 & 0.68 & 3.1 \\
\hline & B12 def (mat) & 47 & 0.067 & 0.088 & 0.11 & 0.20 & 0.25 & 0.31 & 0.39 & 0.67 \\
\hline & MCD & 15 & 0.040 & 0.055 & 0.064 & 0.13 & 0.17 & 0.26 & 0.50 & 0.69 \\
\hline \multirow[t]{7}{*}{$\mathrm{C} 3 / \mathrm{C} 16$} & PROP & 169 & 0.98 & 2.0 & 2.6 & 3.8 & 5.6 & 8.5 & 14 & 44 \\
\hline & MUT/Cbl A,B & 288 & 0.42 & 1.3 & 1.7 & 2.5 & 3.7 & 5.4 & 8.3 & 28 \\
\hline & Cbl C,D & 112 & 0.82 & 1.5 & 1.7 & 2.3 & 3.1 & 4.3 & 5.6 & 12 \\
\hline & CPT-I & 35 & 0.81 & 1.2 & 1.3 & 2.4 & 3.1 & 5.6 & 12 & 19 \\
\hline & B12 def (mat) & 46 & 0.90 & 1.0 & 1.3 & 1.9 & 2.8 & 4.0 & 5.5 & 11 \\
\hline & CPT-I (P479L) & 11 & 0.62 & 0.87 & 1.2 & 1.7 & 2.4 & 3.5 & 5.1 & 10 \\
\hline & MCD & 15 & 0.36 & 0.42 & 0.56 & 1.1 & 1.9 & 3.2 & 5.0 & 13 \\
\hline \multirow[t]{4}{*}{ C3/Met (low) } & CUD (mat) & 67 & 0.007 & 0.010 & 0.011 & 0.015 & 0.021 & 0.034 & 0.046 & 0.065 \\
\hline & CUD & 158 & 0.003 & 0.005 & 0.007 & 0.012 & 0.021 & 0.030 & 0.041 & 0.088 \\
\hline & MET & 85 & 0.005 & 0.007 & 0.008 & 0.012 & 0.018 & 0.028 & 0.040 & 0.068 \\
\hline & $\mathrm{HCY}$ & 64 & 0.001 & 0.002 & 0.004 & 0.008 & 0.013 & 0.025 & 0.032 & 0.30 \\
\hline \multirow[t]{7}{*}{$\mathrm{C} 3 / \mathrm{Met}$} & Cbl C,D & 110 & 0.11 & 0.16 & 0.23 & 0.35 & 0.73 & 1.3 & 1.6 & 2.5 \\
\hline & PROP & 127 & 0.12 & 0.22 & 0.25 & 0.42 & 0.62 & 1.1 & 1.5 & 6.8 \\
\hline & MUT/Cbl A,B & 256 & 0.046 & 0.12 & 0.19 & 0.26 & 0.40 & 0.56 & 0.99 & 3.2 \\
\hline & B12 def (mat) & 47 & 0.082 & 0.11 & 0.13 & 0.21 & 0.30 & 0.44 & 0.68 & 1.0 \\
\hline & MTHFR & 4 & 0.089 & 0.10 & 0.12 & 0.18 & 0.22 & 0.28 & 0.36 & 0.41 \\
\hline & $\mathrm{Cbl} \mathrm{G}$ & 3 & 0.15 & 0.15 & 0.16 & 0.17 & 0.20 & 0.30 & 0.36 & 0.39 \\
\hline & $\mathrm{Cbl} \mathrm{E}$ & 1 & 0.19 & 0.19 & 0.19 & 0.19 & 0.19 & 0.19 & 0.19 & 0.19 \\
\hline \multirow[t]{5}{*}{$\mathrm{C} 4 / \mathrm{C} 2$} & SCAD & 449 & 0.024 & 0.034 & 0.040 & 0.052 & 0.069 & 0.092 & 0.13 & 0.19 \\
\hline & GA-II & 84 & 0.008 & 0.010 & 0.015 & 0.027 & 0.067 & 0.14 & 0.35 & 1.6 \\
\hline & IBG & 56 & 0.025 & 0.032 & 0.042 & 0.051 & 0.064 & 0.085 & 0.11 & 0.19 \\
\hline & $\mathrm{EE}$ & 6 & 0.052 & 0.053 & 0.055 & 0.059 & 0.064 & 0.096 & 0.18 & 0.24 \\
\hline & FIGLU & 25 & 0.026 & 0.029 & 0.038 & 0.050 & 0.062 & 0.091 & 0.15 & 0.18 \\
\hline \multirow[t]{5}{*}{ C4/C3 (low) } & MCD & 11 & 0.016 & 0.016 & 0.017 & 0.024 & 0.059 & 0.096 & 0.11 & 0.16 \\
\hline & B12 def (mat) & 47 & 0.027 & 0.028 & 0.030 & 0.041 & 0.052 & 0.070 & 0.083 & 0.11 \\
\hline & Cbl C,D & 104 & 0.015 & 0.018 & 0.020 & 0.026 & 0.039 & 0.059 & 0.094 & 0.21 \\
\hline & MUT/Cbl A,B & 264 & 0.008 & 0.013 & 0.015 & 0.020 & 0.031 & 0.047 & 0.067 & 0.22 \\
\hline & PROP & 134 & 0.004 & 0.007 & 0.008 & 0.011 & 0.018 & 0.028 & 0.040 & 0.059 \\
\hline
\end{tabular}


Table 5 Continued

\begin{tabular}{|c|c|c|c|c|c|c|c|c|c|c|}
\hline \multirow[b]{2}{*}{ Marker } & \multirow[b]{2}{*}{ Condition } & \multirow[b]{2}{*}{$N$} & \multicolumn{8}{|c|}{ Percentiles of disorder ranges } \\
\hline & & & $1 \%$ & $5 \%$ & $10 \%$ & $25 \%$ & $50 \%$ & $75 \%$ & $90 \%$ & $99 \%$ \\
\hline \multirow[t]{5}{*}{$\mathrm{C} 4 / \mathrm{C} 3$} & $\mathrm{EE}$ & 6 & 0.77 & 0.81 & 0.85 & 0.97 & 1.1 & 2.5 & 3.2 & 3.5 \\
\hline & IBG & 66 & 0.41 & 0.54 & 0.62 & 0.76 & 1.0 & 1.3 & 1.6 & 2.1 \\
\hline & FIGLU & 24 & 0.42 & 0.45 & 0.47 & 0.68 & 1.0 & 1.2 & 1.6 & 3.6 \\
\hline & GA-II & 90 & 0.079 & 0.15 & 0.21 & 0.42 & 0.96 & 2.4 & 6.5 & 13 \\
\hline & SCAD & 506 & 0.29 & 0.41 & 0.51 & 0.67 & 0.96 & 1.4 & 1.8 & 3.3 \\
\hline \multirow[t]{4}{*}{$\mathrm{C} 4 / \mathrm{C} 8$} & IBG & 65 & 6.6 & 10 & 11 & 16 & 25 & 36 & 46 & 93 \\
\hline & SCAD & 510 & 6.0 & 10 & 13 & 17 & 25 & 33 & 43 & 89 \\
\hline & $\mathrm{EE}$ & 6 & 8.2 & 8.3 & 8.6 & 10 & 18 & 23 & 45 & 63 \\
\hline & FIGLU & 23 & 6.0 & 7.1 & 7.1 & 11 & 15 & 24 & 54 & 83 \\
\hline \multirow[t]{4}{*}{$\mathrm{C} 5 / \mathrm{C} 0$} & IVA & 183 & 0.012 & 0.031 & 0.046 & 0.087 & 0.16 & 0.41 & 0.72 & 1.6 \\
\hline & $2 \mathrm{MBG}$ & 170 & 0.011 & 0.016 & 0.018 & 0.023 & 0.028 & 0.042 & 0.055 & 0.12 \\
\hline & GA-II & 90 & 0.002 & 0.004 & 0.005 & 0.011 & 0.024 & 0.091 & 0.27 & 0.83 \\
\hline & $\mathrm{EE}$ & 6 & 0.001 & 0.001 & 0.001 & 0.004 & 0.017 & 0.027 & 0.031 & 0.035 \\
\hline \multirow[t]{4}{*}{$\mathrm{C} 5 / \mathrm{C} 2$} & IVA & 166 & 0.012 & 0.032 & 0.057 & 0.10 & 0.18 & 0.43 & 0.74 & 1.3 \\
\hline & GA-II & 84 & 0.002 & 0.004 & 0.006 & 0.014 & 0.035 & 0.15 & 0.41 & 1.0 \\
\hline & $2 \mathrm{MBG}$ & 179 & 0.009 & 0.014 & 0.019 & 0.023 & 0.031 & 0.047 & 0.064 & 0.14 \\
\hline & $\mathrm{EE}$ & 6 & 0.001 & 0.001 & 0.001 & 0.007 & 0.021 & 0.036 & 0.052 & 0.062 \\
\hline \multirow[t]{4}{*}{ C5/C3 (low) } & MCD & 14 & 0.009 & 0.013 & 0.017 & 0.022 & 0.045 & 0.064 & 0.12 & 0.15 \\
\hline & B12 def (mat) & 47 & 0.012 & 0.015 & 0.018 & 0.021 & 0.032 & 0.044 & 0.056 & 0.14 \\
\hline & MUT/Cbl A,B & 270 & 0.006 & 0.011 & 0.014 & 0.018 & 0.025 & 0.035 & 0.048 & 0.12 \\
\hline & PROP & 147 & 0.004 & 0.005 & 0.005 & 0.007 & 0.011 & 0.016 & 0.022 & 0.053 \\
\hline \multirow[t]{4}{*}{$\mathrm{C} 5 / \mathrm{C} 3$} & IVA & 171 & 0.19 & 0.48 & 0.64 & 1.3 & 2.6 & 8.5 & 13 & 29 \\
\hline & GA-II & 90 & 0.034 & 0.063 & 0.082 & 0.20 & 0.55 & 2.3 & 6.8 & 30 \\
\hline & $\mathrm{EE}$ & 6 & 0.005 & 0.009 & 0.013 & 0.10 & 0.43 & 0.80 & 1.0 & 1.1 \\
\hline & $2 \mathrm{MBG}$ & 178 & 0.11 & 0.14 & 0.17 & 0.25 & 0.32 & 0.49 & 0.78 & 1.5 \\
\hline \multirow[t]{7}{*}{$\mathrm{C} 5-\mathrm{OH} / \mathrm{C} 0$} & 3MCC (mat) & 94 & 0.028 & 0.043 & 0.050 & 0.10 & 0.49 & 0.87 & 1.6 & 2.6 \\
\hline & $3 \mathrm{MCC}$ & 491 & 0.019 & 0.026 & 0.031 & 0.048 & 0.10 & 0.28 & 0.51 & 1.2 \\
\hline & HMG & 27 & 0.012 & 0.025 & 0.031 & 0.051 & 0.075 & 0.19 & 0.31 & 0.97 \\
\hline & MCD & 13 & 0.015 & 0.021 & 0.030 & 0.049 & 0.059 & 0.11 & 0.12 & 0.23 \\
\hline & $3 \mathrm{MGA}$ & 16 & 0.031 & 0.032 & 0.038 & 0.046 & 0.056 & 0.069 & 0.089 & 0.15 \\
\hline & 2M3HBA & 1 & 0.054 & 0.054 & 0.054 & 0.054 & 0.054 & 0.054 & 0.054 & 0.054 \\
\hline & $\mathrm{BKT}$ & 19 & 0.020 & 0.025 & 0.026 & 0.033 & 0.051 & 0.066 & 0.075 & 0.092 \\
\hline \multirow[t]{7}{*}{$\mathrm{C} 5-\mathrm{OH} / \mathrm{C} 8$} & $3 \mathrm{MCC}$ (mat) & 97 & 7.4 & 12 & 16 & 30 & 75 & 190 & 291 & 630 \\
\hline & $3 \mathrm{MCC}$ & 502 & 5.3 & 8.3 & 12 & 18 & 40 & 95 & 175 & 378 \\
\hline & MCD & 14 & 1.0 & 4.4 & 8.0 & 14 & 32 & 45 & 51 & 105 \\
\hline & HMG & 28 & 2.2 & 7.1 & 12 & 15 & 21 & 47 & 68 & 82 \\
\hline & $3 \mathrm{MGA}$ & 18 & 8.5 & 9.2 & 9.8 & 14 & 18 & 27 & 38 & 47 \\
\hline & 2M3HBA & 1 & 18 & 18 & 18 & 18 & 18 & 18 & 18 & 18 \\
\hline & $\mathrm{BKT}$ & 19 & 4.0 & 5.2 & 5.4 & 11 & 16 & 21 & 26 & 66 \\
\hline
\end{tabular}


Table 5 Continued

\begin{tabular}{|c|c|c|c|c|c|c|c|c|c|c|}
\hline \multirow[b]{2}{*}{ Marker } & \multirow[b]{2}{*}{ Condition } & \multirow[b]{2}{*}{$N$} & \multicolumn{8}{|c|}{ Percentiles of disorder ranges } \\
\hline & & & $1 \%$ & $5 \%$ & $10 \%$ & $25 \%$ & $50 \%$ & $75 \%$ & $90 \%$ & $99 \%$ \\
\hline \multirow[t]{4}{*}{$\mathrm{C} 8 / \mathrm{C} 2$} & MCAD & 1486 & 0.011 & 0.029 & 0.048 & 0.11 & 0.29 & 0.57 & 0.94 & 1.7 \\
\hline & GA-II & 83 & 0.003 & 0.004 & 0.005 & 0.013 & 0.035 & 0.068 & 0.12 & 0.28 \\
\hline & MCAD (mat) & 3 & 0.004 & 0.005 & 0.007 & 0.013 & 0.022 & 0.023 & 0.024 & 0.024 \\
\hline & MCAD (het) & 119 & 0.004 & 0.005 & 0.006 & 0.007 & 0.010 & 0.018 & 0.033 & 0.14 \\
\hline \multirow[t]{2}{*}{$\mathrm{C} 8 / \mathrm{C} 10$} & MCAD & 1796 & 0.80 & 1.5 & 2.3 & 5.4 & 10 & 13 & 16 & 22 \\
\hline & MCAD (het) & 137 & 0.51 & 0.54 & 0.60 & 0.68 & 0.75 & 0.93 & 1.2 & 6.2 \\
\hline $\mathrm{C} 3-\mathrm{DC} / \mathrm{C} 10$ & MAL & 19 & 5.0 & 5.7 & 6.2 & 11 & 19 & 46 & 67 & 88 \\
\hline \multirow[t]{3}{*}{$\mathrm{C} 5-\mathrm{DC} / \mathrm{C} 5-\mathrm{OH}$} & GA-I & 214 & 0.89 & 1.3 & 1.7 & 3.7 & 7.8 & 15 & 25 & 46 \\
\hline & GA-II & 82 & 0.093 & 0.22 & 0.40 & 1.0 & 2.3 & 3.9 & 9.1 & 26 \\
\hline & GA-I (mat) & 2 & 0.96 & 1.1 & 1.2 & 1.6 & 2.2 & 2.9 & 3.2 & 3.5 \\
\hline $\mathrm{C} 5-\mathrm{DC} / \mathrm{C} 8$ & GA-I & 224 & 0.94 & 1.7 & 3.1 & 7.5 & 16 & 34 & 70 & 163 \\
\hline \multirow[t]{2}{*}{$\mathrm{C} 5-\mathrm{DC} / \mathrm{C} 16$} & GA-I & 242 & 0.034 & 0.062 & 0.11 & 0.20 & 0.44 & 0.84 & 1.6 & 6.1 \\
\hline & GA-I (mat) & 2 & 0.15 & 0.16 & 0.16 & 0.17 & 0.18 & 0.20 & 0.21 & 0.22 \\
\hline \multirow[t]{4}{*}{$\mathrm{C} 14: 1 / \mathrm{C} 2$} & VLCAD & 329 & 0.016 & 0.025 & 0.030 & 0.043 & 0.089 & 0.18 & 0.31 & 0.71 \\
\hline & GA-II & 82 & 0.002 & 0.005 & 0.008 & 0.023 & 0.062 & 0.089 & 0.14 & 0.35 \\
\hline & LCHAD/TFP & 125 & 0.004 & 0.009 & 0.011 & 0.019 & 0.039 & 0.062 & 0.11 & 0.15 \\
\hline & VLCAD (het) & 87 & 0.015 & 0.017 & 0.020 & 0.024 & 0.030 & 0.036 & 0.048 & 0.062 \\
\hline \multirow[t]{2}{*}{ C14:1/C12:1 } & VLCAD & 242 & 1.1 & 1.6 & 2.1 & 3.3 & 5.2 & 10 & 18 & 38 \\
\hline & VLCAD (het) & 59 & 0.93 & 1.1 & 1.2 & 1.5 & 2.0 & 2.4 & 2.9 & 4.4 \\
\hline \multirow[t]{4}{*}{$\mathrm{C} 14: 1 / \mathrm{C} 16$} & VLCAD & 400 & 0.059 & 0.18 & 0.22 & 0.28 & 0.41 & 0.59 & 0.83 & 1.8 \\
\hline & VLCAD (het) & 87 & 0.12 & 0.13 & 0.15 & 0.18 & 0.24 & 0.32 & 0.37 & 0.50 \\
\hline & GA-II & 90 & 0.016 & 0.033 & 0.044 & 0.097 & 0.22 & 0.31 & 0.42 & 0.60 \\
\hline & LCHAD/TFP & 140 & 0.035 & 0.058 & 0.084 & 0.14 & 0.20 & 0.30 & 0.44 & 0.79 \\
\hline \multirow[t]{2}{*}{$(\mathrm{C} 16+\mathrm{C} 18: 1) / \mathrm{C} 2$ (low) } & CPT-I (P479L) & 11 & 0.030 & 0.032 & 0.034 & 0.054 & 0.073 & 0.092 & 0.14 & 0.36 \\
\hline & CPT-I & 34 & 0.007 & 0.011 & 0.014 & 0.020 & 0.039 & 0.070 & 0.083 & 0.11 \\
\hline \multirow[t]{2}{*}{$(\mathrm{C} 16+\mathrm{C} 18: 1) / \mathrm{C} 2$} & CPT-II & 32 & 0.20 & 0.27 & 0.40 & 0.96 & 2.2 & 5.3 & 10 & 20 \\
\hline & CACT & 7 & 0.25 & 0.28 & 0.33 & 0.59 & 1.8 & 2.9 & 20 & 42 \\
\hline $\mathrm{C} 16-\mathrm{OH} / \mathrm{C} 16$ & LCHAD/TFP & 142 & 0.025 & 0.072 & 0.10 & 0.17 & 0.26 & 0.38 & 0.44 & 0.69 \\
\hline C18-OH/C18 & LCHAD/TFP & 97 & 0.013 & 0.062 & 0.14 & 0.39 & 0.67 & 0.96 & 1.2 & 1.5 \\
\hline
\end{tabular}

For abbreviations of analytes and conditions, see legends of Table 1 and Figure 2, respectively. Acylcarnitine ratios are listed in increasing molecular weight order of the numerator. When multiple conditions are shown, they are sorted by descending order (highest first) of the median values of the disorder range.

normal population that they trigger very large numbers of false positive events.

In addition, Tables $6-8$ also present the distribution of cutoff values below, within, and above the respective target range. Overall, $42 \%(2269 / 5341)$ of all submitted values are within the target range, $15 \%$ (788) are positioned to have low specificity but high sensitivity, and the rest $(43 \%, 2282 / 5341)$ are set at a level where false negative outcomes are likely to occur. The most striking observation is that $42 \%$ of these cutoffs with potentially poor sensitivity are applied to 37 markers with no overlap between normal population and disorder range. This group should be scrutinized closely to identify adjustments, which could be relatively easy to implement in the pursuit of performance improvement.

\section{DISCUSSION}

We have reported the status of a worldwide collaborative project aimed at laboratory quality improvement of newborn screening by MS/MS. The central strategy of this effort is to assemble enough evidence to establish clinical utility using a more effective method for the selection of cutoff values. Traditionally, this is done by statistical elaboration, either as a given percentile of the normal population or by adding multi- 
Table 6 Low cutoff target ranges of amino acids, acylcarnitines, and ratios

\begin{tabular}{|c|c|c|c|c|c|c|c|c|c|c|c|c|c|}
\hline \multirow[b]{3}{*}{ Analyte } & \multirow{3}{*}{$\begin{array}{l}\text { No. of } \\
\text { cases }\end{array}$} & \multirow{3}{*}{$\begin{array}{l}\text { No. of } \\
\text { conditions }\end{array}$} & \multirow{3}{*}{$\begin{array}{c}\mathrm{O} / \mathrm{R} \\
99 \% \text { ile } \\
\mathrm{DR}^{a}\end{array}$} & \multirow{2}{*}{\multicolumn{3}{|c|}{$\begin{array}{l}\text { Low cutoff } \\
\text { target range }\end{array}$}} & \multirow{3}{*}{$\begin{array}{c}\mathrm{O} / \mathrm{R} \\
1 \% \text { ile } \\
\mathrm{NP}^{b}\end{array}$} & \multicolumn{6}{|c|}{$\begin{array}{c}\text { Current cutoff } \\
\text { values }(n=638)\end{array}$} \\
\hline & & & & & & & & \multicolumn{2}{|r|}{ Below } & \multicolumn{2}{|r|}{ Within } & \multicolumn{2}{|r|}{ Above } \\
\hline & & & & Lo & & High & & $N$ & Percentage & $N$ & Percentage & $N$ & Percentage \\
\hline Arg & 46 & 2 & Yes & 2.0 & - & 5.0 & Yes & 12 & 33 & 24 & 67 & 0 & 0 \\
\hline Cit & 60 & 2 & Yes & 4.0 & - & 6.0 & Yes & 16 & 33 & 26 & 54 & 6 & 13 \\
\hline Cit/Arg & 63 & 2 & No & 0.29 & - & 0.42 & No & 0 & 0 & 8 & 89 & 1 & 11 \\
\hline Cit/Phe & 60 & 2 & Yes & 0.070 & - & 0.11 & No & 1 & 7 & 11 & 79 & 2 & 14 \\
\hline Gln/Cit & 5 & 1 & No & 1.4 & - & 3.9 & No & 0 & 0 & 1 & 100 & 0 & 0 \\
\hline Met & 8 & 3 & No & 9.8 & - & 11 & No & 27 & 63 & 7 & 16 & 9 & 21 \\
\hline Met/Cit & 9 & 4 & Yes & 0.80 & - & 1.1 & Yes & 2 & 50 & 2 & 50 & 0 & 0 \\
\hline Met/Phe & 8 & 3 & No & 0.17 & - & 0.23 & No & 6 & 23 & 18 & 69 & 2 & 8 \\
\hline Met/Tyr & 9 & 4 & Yes & 0.10 & - & 0.12 & Yes & 1 & 25 & 3 & 75 & 0 & 0 \\
\hline Met/Xle & 9 & 4 & Yes & 0.10 & - & 0.12 & Yes & 2 & 33 & 4 & 67 & 0 & 0 \\
\hline $\mathrm{C} 0$ & 388 & 5 & Yes & 7.5 & - & 12 & Yes & 32 & 32 & 55 & 56 & 12 & 12 \\
\hline $\mathrm{C} 0 /(\mathrm{C} 16+\mathrm{C} 18)$ & 39 & 2 & Yes & 2.0 & - & 3.1 & No & 8 & 19 & 23 & 53 & 12 & 28 \\
\hline $\mathrm{ACs} / \mathrm{Cit}^{c}$ & 166 & 2 & Yes & 2.0 & - & 3.0 & Yes & 3 & 21 & 10 & 71 & 1 & 7 \\
\hline $\mathrm{C} 2$ & 290 & 4 & Yes & 7 & - & 10 & No & 18 & 38 & 18 & 38 & 11 & 23 \\
\hline $\mathrm{C} 3$ & 244 & 2 & Yes & 0.55 & - & 1.0 & Yes & 12 & 55 & 10 & 45 & 0 & 0 \\
\hline $\mathrm{C} 3 / \mathrm{Met}$ & 374 & 4 & Yes & 0.040 & - & 0.050 & Yes & 1 & 17 & 4 & 67 & 1 & 17 \\
\hline $\mathrm{C} 4 / \mathrm{C} 3$ & 560 & 6 & Yes & 0.040 & - & 0.060 & Yes & 2 & 40 & 3 & 60 & 0 & 0 \\
\hline $\mathrm{C} 5 / \mathrm{C} 3$ & 478 & 5 & Yes & 0.020 & - & 0.040 & Yes & 0 & 0 & 4 & 100 & 0 & 0 \\
\hline $\mathrm{C} 16$ & 316 & 3 & NA & Less $\mathrm{t}$ & & 0.80 & No & 0 & 0 & 52 & 81 & 12 & 19 \\
\hline$(\mathrm{C} 16+\mathrm{C} 18: 1) / \mathrm{C} 2$ & 45 & 1 & Yes & 0.080 & - & 0.10 & Yes & 4 & 27 & 10 & 67 & 1 & 7 \\
\hline C18:2 & 44 & 2 & NA & Less $t$ & & 0.057 & Yes & 0 & 0 & 28 & 90 & 3 & 10 \\
\hline C18:1 & 259 & 5 & NA & Less $\mathrm{t}$ & & 0.49 & Yes & 0 & 0 & 32 & 70 & 14 & 30 \\
\hline $\mathrm{C} 18$ & 252 & 5 & NA & Less $t$ & & 0.31 & Yes & 0 & 0 & 36 & 73 & 13 & 27 \\
\hline
\end{tabular}

${ }^{a}$ This column indicates an override $(\mathrm{O} / \mathrm{R})$ of the target range first element ( $99 \%$ ile of the cumulative disorder range) to increase specificity and reduce the occurrence of false positive results.

${ }^{b}$ This column indicates an override $(\mathrm{O} / \mathrm{R})$ of the target range second element (1\%ile of the cumulative normal population) to increase sensitivity and reduce a significant risk of false negative results.

${ }^{c} \mathrm{ACs} / \mathrm{Cit},(\mathrm{C} 0+\mathrm{C} 2+\mathrm{C} 3+\mathrm{C} 16+\mathrm{C} 18: 1) / \mathrm{Cit}$ ratio. For abbreviations of other analytes, see legends of Table 1.

NA, not available.

ples of the standard deviation to the mean value. Hence, the criteria to define abnormality are almost exclusively based on normal results. Once cutoffs selected in this manner are implemented, negative feedback from the follow-up system (too many false positives) or the dreaded occurrence of a false negative case may lead to abrupt changes, often resulting in the opposite problem. This situation is compounded by the reality that most programs have actually never encountered a case affected with $30-80 \%$ of the conditions that they are testing for. A large repository of true positive cases exists and could have been helpful to advance this project further, but it is under the control of a commercial entity, and the information is treated as proprietary. ${ }^{32}$ However, four programs who outsource testing to the same company have nevertheless joined the project and have submitted limited sets of data (true positive cases only).
In the interest of time, and particularly of the vulnerable population we serve, the lack of available information had to be addressed because of the anecdotal nature of single site experiences and of the inherent risk of making uninformed choices. These are often caused by limited familiarity with the complexity of the biochemical phenotype of metabolic disorders and to some extent with the technology being used.

Tolerance of some degree of analytical variability and an unprecedented willingness to share data have resulted in a vast body of evidence, which has been used for clinical validation of amino acid and acylcarnitine cutoff values. Rather than the conventional statistical approach, we have sought the definition of gaps in analyte concentrations between the normal population and the disorder range of rare disorders. These gaps were either naturally occurring or carefully selected by consensus 
Table 7 High cutoff target ranges of amino acids and amino acid ratios

\begin{tabular}{|c|c|c|c|c|c|c|c|c|c|c|c|c|c|}
\hline \multirow[b]{3}{*}{ Analyte } & \multirow{3}{*}{$\begin{array}{l}\text { No. of } \\
\text { cases }\end{array}$} & \multirow{3}{*}{$\begin{array}{l}\text { No. of } \\
\text { conditions }\end{array}$} & \multirow{3}{*}{$\begin{array}{c}\mathrm{O} / \mathrm{R} \\
99 \% \text { ile } \\
\mathrm{NP}^{a}\end{array}$} & \multirow{2}{*}{\multicolumn{3}{|c|}{$\begin{array}{l}\text { High cutoff } \\
\text { target range }\end{array}$}} & \multirow{3}{*}{$\begin{array}{c}\mathrm{O} / \mathrm{R} \\
5 \% \text { ile } \\
\mathrm{DR}^{b}\end{array}$} & \multicolumn{6}{|c|}{$\begin{array}{c}\text { Current cutoff } \\
\text { values }(n=1533)\end{array}$} \\
\hline & & & & & & & & \multicolumn{2}{|r|}{ Below } & \multicolumn{2}{|c|}{ Within } & \multicolumn{2}{|r|}{ Above } \\
\hline & & & & Low & & High & & $N$ & Percentage & $N$ & Percentage & $N$ & Percentage \\
\hline Ala & 49 & 2 & No & 507 & - & 700 & Yes & 12 & 27 & 22 & 49 & 11 & 24 \\
\hline Arg & 22 & 1 & No & 32 & - & 40 & Yes & 21 & 26 & 14 & 17 & 47 & 57 \\
\hline Arg/Ala & 14 & 1 & No & 0.11 & - & 0.15 & No & 1 & 20 & 2 & 40 & 2 & 40 \\
\hline Arg/Phe & 17 & 1 & No & 0.59 & - & 0.75 & No & 1 & 17 & 4 & 67 & 1 & 17 \\
\hline Asa & 51 & 1 & No & 0.66 & - & 0.90 & Yes & 8 & 28 & 8 & 28 & 13 & 45 \\
\hline Asa/Arg & 44 & 1 & No & 0.18 & - & 0.25 & Yes & 6 & 46 & 4 & 31 & 3 & 23 \\
\hline Cit & 385 & 5 & No & 28 & - & 40 & Yes & 11 & 11 & 26 & 26 & 62 & 63 \\
\hline Cit/Arg & 255 & 5 & No & 4.9 & - & 6.0 & Yes & 12 & 23 & 21 & 40 & 19 & 37 \\
\hline Cit/Phe & 308 & 5 & No & 0.54 & - & 0.61 & Yes & 3 & 18 & 7 & 41 & 7 & 41 \\
\hline Gln & 28 & 2 & No & 117 & - & 150 & Yes & 0 & 0 & 5 & 83 & 1 & 17 \\
\hline Gln/Cit & 28 & 2 & No & 14 & - & 20 & Yes & 0 & 0 & 3 & 100 & 0 & 0 \\
\hline Glu & 31 & 2 & Yes & 300 & - & 400 & Yes & 2 & 8 & 6 & 24 & 17 & 68 \\
\hline Glu/Cit & 31 & 2 & No & 50 & - & 54 & Yes & 2 & 33 & 2 & 33 & 2 & 33 \\
\hline Gly & 44 & 1 & Yes & 500 & - & 700 & Yes & 4 & 7 & 13 & 23 & 40 & 70 \\
\hline Met & 182 & 2 & No & 44 & - & 48 & No & 20 & 20 & 15 & 15 & 66 & 65 \\
\hline Met/Cit & 208 & 4 & Yes & 4.0 & - & 4.5 & Yes & 2 & 40 & 1 & 20 & 2 & 40 \\
\hline Met/Phe & 161 & 2 & No & 0.74 & - & 0.99 & No & 8 & 12 & 16 & 24 & 43 & 64 \\
\hline Met/Tyr & 153 & 2 & Yes & 0.55 & - & 0.65 & Yes & 1 & 25 & 3 & 75 & 0 & 0 \\
\hline Met/Xle & 146 & 2 & Yes & 0.33 & - & 0.37 & Yes & 5 & 63 & 2 & 25 & 1 & 13 \\
\hline Phe & 3129 & 4 & No & 97 & - & 135 & No & 12 & 11 & 54 & 49 & 45 & 41 \\
\hline Phe/Tyr & 2847 & 4 & No & 1.6 & - & 2.5 & Yes & 21 & 21 & 64 & 63 & 16 & 16 \\
\hline Suac & 60 & 1 & No & 1.4 & - & 7.5 & No & 6 & 18 & 25 & 76 & 2 & 6 \\
\hline Tyr & 204 & 4 & No & 207 & - & 226 & No & 24 & 24 & 15 & 15 & 62 & 61 \\
\hline Val & 199 & 1 & Yes & 180 & - & 220 & Yes & 8 & 9 & 23 & 25 & 61 & 66 \\
\hline $\mathrm{Val} / \mathrm{Phe}$ & 172 & 1 & Yes & 3.0 & - & 3.5 & Yes & 5 & 10 & 20 & 41 & 24 & 49 \\
\hline Xle & 236 & 1 & No & 235 & - & 260 & No & 17 & 16 & 16 & 15 & 71 & 68 \\
\hline Xle/Ala & 145 & 1 & No & 1.0 & - & 1.5 & Yes & 6 & 12 & 30 & 61 & 13 & 27 \\
\hline Xle/Phe & 193 & 1 & Yes & 3.5 & - & 3.8 & No & 4 & 6 & 11 & 16 & 55 & 79 \\
\hline
\end{tabular}

For abbreviations of analytes, see legends of Table 1.

${ }^{a}$ This column indicates an override $(\mathrm{O} / \mathrm{R})$ of the target range first element ( $99 \%$ ile of the cumulative normal population) to increase sensitivity and reduce a significant risk of false negative results.

${ }^{b}$ This column indicates an override $(\mathrm{O} / \mathrm{R})$ of the target range second element ( $5 \%$ ile of the cumulative disorder range) to increase specificity and reduce the occurrence of false positive results.

expert opinion. This approach leads to a substantial expansion of the number of markers, which are potentially informative for a condition, both at the high and low end. In some cases, new associations between a marker and a condition are documented. For example, our database has confirmed a previously reported, and somewhat unexpected, association between disorders of propionate metabolism and an elevated concentration of hydroxy hexedecenoylcarnitine $(\mathrm{C} 16: 1-\mathrm{OH}) .{ }^{33}$ Despite causing some initial consternation among new users, broadening the definition of clinical significance is critical to explain how cutoff values should not be used, a boundary between normal and abnormal, and place them instead in a role of review flags calling attention to cases that require an assessment in terms of pattern recognition and profile interpretation. ${ }^{34}$ Clearly, there remain conditions with only a very small number of cases $(<5)$, and the disorder ranges are at this stage merely 
Table 8 High cutoff target ranges of acylcarnitines and acylcarnitine ratios

\begin{tabular}{|c|c|c|c|c|c|c|c|c|c|c|c|c|c|}
\hline \multirow[b]{3}{*}{ Analyte } & \multirow{3}{*}{$\begin{array}{l}\text { No. of } \\
\text { cases }\end{array}$} & \multirow{3}{*}{$\begin{array}{l}\text { No. of } \\
\text { conditions }\end{array}$} & \multirow{3}{*}{$\begin{array}{c}\mathrm{O} / \mathrm{R} \\
99 \% \text { ile } \\
\mathrm{NP}^{a}\end{array}$} & \multirow{2}{*}{\multicolumn{3}{|c|}{$\begin{array}{l}\text { High cutoff } \\
\text { target range }\end{array}$}} & \multirow{3}{*}{$\begin{array}{c}\mathrm{O} / \mathrm{R} \\
5 \% \text { ile } \\
\mathrm{DR}^{b}\end{array}$} & \multicolumn{6}{|c|}{$\begin{array}{l}\text { Current cutoff values compared } \\
\text { with target range }\end{array}$} \\
\hline & & & & & & & & \multicolumn{2}{|r|}{ Below } & \multicolumn{2}{|r|}{ Within } & \multicolumn{2}{|r|}{ Above } \\
\hline & & & & Low & & High & & $N$ & Percentage & $N$ & Percentage & $N$ & Percentage \\
\hline $\mathrm{C} 0$ & 67 & 2 & No & 59 & - & 65 & No & 17 & 20 & 18 & 21 & 51 & 59 \\
\hline $\mathrm{ACs} / \mathrm{Cit}$ & 47 & 2 & Yes & 10 & - & 15 & Yes & 1 & 20 & 2 & 40 & 2 & 40 \\
\hline $\mathrm{C} 0 /(\mathrm{C} 16+\mathrm{C} 18)$ & 65 & 2 & No & 27 & - & 30 & Yes & 13 & 21 & 13 & 21 & 36 & 58 \\
\hline $\mathrm{C} 3$ & 715 & 6 & No & 4.7 & - & 5.5 & Yes & 18 & 18 & 32 & 32 & 49 & 49 \\
\hline $\mathrm{C} 3 / \mathrm{C} 2$ & 667 & 6 & No & 0.18 & - & 0.20 & Yes & 11 & 12 & 39 & 41 & 45 & 47 \\
\hline $\mathrm{C} 3 / \mathrm{C} 16$ & 676 & 8 & Yes & 1.7 & - & 2.0 & Yes & 7 & 14 & 17 & 33 & 27 & 53 \\
\hline C3/Met & 548 & 6 & No & 0.29 & - & 0.40 & Yes & 11 & 52 & 5 & 24 & 5 & 24 \\
\hline $\mathrm{C} 4$ & 787 & 5 & No & 0.75 & - & 1.1 & No & 10 & 11 & 32 & 36 & 46 & 52 \\
\hline $\mathrm{C} 4 / \mathrm{C} 2$ & 620 & 5 & No & 0.03 & - & 0.04 & Yes & 3 & 6 & 22 & 42 & 27 & 52 \\
\hline $\mathrm{C} 4 / \mathrm{C} 3$ & 692 & 5 & No & 0.44 & - & 0.50 & Yes & 5 & 10 & 16 & 31 & 30 & 59 \\
\hline $\mathrm{C} 4 / \mathrm{C} 8$ & 604 & 4 & No & 13.9 & - & 15.0 & Yes & 4 & 13 & 9 & 29 & 18 & 58 \\
\hline C5:1 & 24 & 2 & No & 0.08 & - & 0.24 & No & 5 & 6 & 54 & 64 & 26 & 31 \\
\hline C5 & 532 & 4 & No & 0.39 & - & 0.47 & No & 3 & 3 & 17 & 17 & 83 & 81 \\
\hline $\mathrm{C} 5 / \mathrm{C} 0$ & 452 & 4 & No & 0.017 & - & 0.031 & No & 4 & 10 & 28 & 70 & 8 & 20 \\
\hline $\mathrm{C} 5 / \mathrm{C} 2$ & 438 & 4 & No & 0.021 & - & 0.032 & No & 8 & 13 & 24 & 40 & 28 & 47 \\
\hline $\mathrm{C} 5 / \mathrm{C} 3$ & 445 & 4 & No & 0.33 & - & 0.48 & No & 13 & 23 & 17 & 30 & 27 & 47 \\
\hline C4-OH (D) & 14 & 2 & No & 0.49 & - & 0.77 & No & 8 & 17 & 22 & 48 & 16 & 35 \\
\hline C4-OH\&C3-DC (U) & 36 & 2 & No & 0.33 & - & 0.69 & No & 1 & 8 & 6 & 50 & 5 & 42 \\
\hline $\mathrm{C} 4-\mathrm{OH} \& \mathrm{C} 3-\mathrm{DC}(\mathrm{U}) / \mathrm{C} 10$ & 19 & 1 & No & 3.56 & - & 5.72 & No & 0 & 0 & 2 & 50 & 2 & 50 \\
\hline C6 & 1922 & 3 & No & 0.18 & - & 0.24 & No & 13 & 14 & 33 & 34 & 50 & 52 \\
\hline C5-OH (D) & 836 & 8 & No & 0.38 & - & 0.69 & No & 5 & 6 & 41 & 53 & 31 & 40 \\
\hline C5-OH\&C4-DC (U) & 835 & 7 & No & 0.45 & - & 0.69 & No & 1 & 5 & 5 & 25 & 14 & 70 \\
\hline $\mathrm{C} 5-\mathrm{OH}(\mathrm{D}) / \mathrm{C} 0$ & 669 & 7 & No & 0.016 & - & 0.026 & No & 0 & 0 & 15 & 68 & 7 & 32 \\
\hline $\mathrm{C} 5-\mathrm{OH} \& \mathrm{C} 4-\mathrm{DC}(\mathrm{U}) / \mathrm{C} 0$ & 668 & 6 & No & 0.020 & - & 0.026 & No & 0 & 0 & 2 & 33 & 4 & 67 \\
\hline $\mathrm{C} 5-\mathrm{OH}(\mathrm{D}) / \mathrm{C} 8$ & 687 & 7 & No & 8.2 & - & 10 & Yes & 7 & 19 & 12 & 32 & 18 & 49 \\
\hline $\mathrm{C} 5-\mathrm{OH} \& \mathrm{C} 4-\mathrm{DC}(\mathrm{U}) / \mathrm{C} 8$ & 686 & 6 & No & 8.3 & - & 10 & Yes & 1 & 17 & 1 & 17 & 4 & 67 \\
\hline C6-OH (D) & 1 & 1 & Yes & 0.10 & - & 0.12 & No & 0 & 0 & 6 & 50 & 6 & 50 \\
\hline $\mathrm{C} 8$ & 2287 & 4 & No & 0.21 & - & 0.71 & No & 6 & 6 & 98 & 90 & 5 & 5 \\
\hline $\mathrm{C} 8 / \mathrm{C} 2$ & 1711 & 4 & No & 0.011 & - & 0.030 & No & 15 & 25 & 28 & 46 & 18 & 30 \\
\hline $\mathrm{C} 8 / \mathrm{C} 10$ & 1953 & 2 & No & 2.3 & - & 3.0 & Yes & 30 & 35 & 34 & 40 & 21 & 25 \\
\hline C3-DC\&C8-OH (D) & 930 & 2 & No & 0.15 & - & 0.44 & No & 9 & 23 & 30 & 75 & 1 & 3 \\
\hline C3-DC\&C8-OH (D)/C10 & 19 & 1 & No & 2.7 & - & 5.7 & No & 5 & 28 & 10 & 56 & 3 & 17 \\
\hline $\mathrm{C} 10: 2$ & 1 & 1 & No & 0.08 & - & 0.12 & No & 2 & 5 & 19 & 44 & 22 & 51 \\
\hline $\mathrm{C} 10: 1$ & 1755 & 2 & No & 0.17 & - & 0.25 & Yes & 9 & 10 & 34 & 38 & 46 & 52 \\
\hline $\mathrm{C} 10$ & 2047 & 2 & No & 0.26 & - & 0.30 & Yes & 8 & 9 & 23 & 25 & 62 & 67 \\
\hline C4-DC (D) & 175 & 2 & Yes & 0.40 & - & 0.50 & Yes & 2 & 9 & 2 & 9 & 18 & 82 \\
\hline C5-DC\&C10-OH (D) & 1870 & 5 & Yes & 0.10 & - & 0.21 & No & 0 & 0 & 36 & 57 & 27 & 43 \\
\hline & & & & & & & & & & & & & (Continued) \\
\hline
\end{tabular}




\begin{tabular}{|c|c|c|c|c|c|c|c|c|c|c|c|c|c|}
\hline \multirow[b]{3}{*}{ Analyte } & \multirow{3}{*}{$\begin{array}{l}\text { No. of } \\
\text { cases }\end{array}$} & \multirow{3}{*}{$\begin{array}{l}\text { No. of } \\
\text { conditions }\end{array}$} & \multirow{3}{*}{$\begin{array}{c}\mathrm{O} / \mathrm{R} \\
99 \% \text { ile } \\
\mathrm{NP}^{a}\end{array}$} & \multirow{2}{*}{\multicolumn{3}{|c|}{$\begin{array}{l}\text { High cutoff } \\
\text { target range }\end{array}$}} & \multirow{3}{*}{$\begin{array}{l}\mathrm{O} / \mathrm{R} 5 \% \\
\text { ile } \mathrm{DR}^{b}\end{array}$} & \multicolumn{6}{|c|}{$\begin{array}{l}\text { Current cutoff values compared } \\
\text { with target range }\end{array}$} \\
\hline & & & & & & & & \multirow[b]{2}{*}{$N$} & Below & \multicolumn{2}{|r|}{ Within } & \multicolumn{2}{|r|}{ Above } \\
\hline & & & & Low & & High & & & Percentage & $N$ & Percentage & $N$ & Percentage \\
\hline C5-DC\&C6-OH (U) & 366 & 3 & Yes & 0.10 & - & 0.18 & No & 0 & 0 & 1 & 8 & 12 & 92 \\
\hline $\mathrm{C} 5-\mathrm{DC} \& \mathrm{C} 10-\mathrm{OH}(\mathrm{D}) / \mathrm{C} 5-\mathrm{OH}$ & 299 & 3 & No & 1.4 & - & 1.5 & Yes & 9 & 41 & 2 & 9 & 11 & 50 \\
\hline C5-DC\&C6-OH (U)/C5-OH & 299 & 3 & No & 1.0 & - & 1.5 & Yes & 1 & 25 & 1 & 25 & 2 & 50 \\
\hline C5-DC\&C10-OH (D)/C8 & 225 & 1 & Yes & 1.2 & - & 1.7 & No & 3 & 8 & 12 & 31 & 24 & 62 \\
\hline C5-DC\&C6-OH (U)/C8 & 225 & 1 & Yes & 1.2 & - & 1.7 & No & 0 & 0 & 0 & 0 & 6 & 100 \\
\hline C5-DC\&C10-OH (D)/C16 & 245 & 2 & Yes & 0.030 & - & 0.062 & No & 0 & 0 & 11 & 31 & 25 & 69 \\
\hline C5-DC\&C6-OH (U)/C16 & 245 & 2 & Yes & 0.030 & - & 0.059 & No & 0 & 0 & 0 & 0 & 6 & 100 \\
\hline $\mathrm{C} 12: 1$ & 354 & 3 & No & 0.27 & - & 0.50 & Yes & 5 & 9 & 43 & 80 & 6 & 11 \\
\hline $\mathrm{C} 12$ & 459 & 5 & No & 0.41 & - & 0.80 & Yes & 13 & 19 & 47 & 69 & 8 & 12 \\
\hline C6-DC & 17 & 1 & Yes & 0.10 & - & 0.12 & Yes & 4 & 6 & 16 & 23 & 50 & 71 \\
\hline $\mathrm{C} 14: 2$ & 492 & 5 & No & 0.09 & - & 0.15 & Yes & 5 & 8 & 35 & 55 & 24 & 38 \\
\hline $\mathrm{C} 14: 1$ & 777 & 5 & No & 0.37 & - & 0.71 & No & 11 & 11 & 80 & 78 & 12 & 12 \\
\hline $\mathrm{C} 14: 1 / \mathrm{C} 2$ & 624 & 5 & No & 0.016 & - & 0.025 & No & 4 & 15 & 16 & 62 & 6 & 23 \\
\hline C14:1/C12:1 & 301 & 2 & Yes & 4.5 & - & 5.0 & Yes & 14 & 33 & 12 & 29 & 16 & 38 \\
\hline $\mathrm{C} 14: 1 / \mathrm{C} 16$ & 718 & 5 & No & 0.13 & - & 0.18 & No & 7 & 11 & 18 & 30 & 36 & 59 \\
\hline $\mathrm{C} 14$ & 772 & 7 & No & 0.50 & - & 0.80 & Yes & 9 & 10 & 66 & 72 & 17 & 18 \\
\hline $\mathrm{C} 16$ & 62 & 2 & No & 6.0 & - & 7.1 & No & 13 & 13 & 29 & 30 & 56 & 57 \\
\hline$(\mathrm{C} 16+\mathrm{C} 18: 1) / \mathrm{C} 2$ & 39 & 2 & No & 0.31 & - & 0.50 & Yes & 3 & 14 & 17 & 77 & 2 & 9 \\
\hline C18:2 & 28 & 2 & No & 0.60 & - & 0.65 & No & 10 & 18 & 19 & 33 & 28 & 49 \\
\hline C18:1 & 48 & 2 & No & 2.5 & - & 2.7 & Yes & 15 & 17 & 13 & 15 & 58 & 67 \\
\hline $\mathrm{C} 18$ & 44 & 2 & No & 1.7 & - & 1.9 & Yes & 12 & 15 & 17 & 21 & 51 & 64 \\
\hline $\mathrm{C} 16: 1-\mathrm{OH}$ & 239 & 5 & Yes & 0.10 & - & 0.15 & Yes & 2 & 3 & 31 & 53 & 26 & 44 \\
\hline $\mathrm{C} 16-\mathrm{OH}$ & 169 & 2 & No & 0.08 & - & 0.19 & No & 9 & 9 & 77 & 75 & 17 & 17 \\
\hline $\mathrm{C} 16-\mathrm{OH} / \mathrm{C} 16$ & 143 & 2 & No & 0.033 & - & 0.072 & No & 1 & 2 & 24 & 50 & 23 & 48 \\
\hline C18:1-OH & 154 & 2 & No & 0.07 & - & 0.08 & No & 8 & 9 & 14 & 16 & 66 & 75 \\
\hline $\mathrm{C} 18-\mathrm{OH}$ & 118 & 3 & No & 0.06 & - & 0.10 & Yes & 5 & 8 & 40 & 62 & 20 & 31 \\
\hline $\mathrm{C} 18-\mathrm{OH} / \mathrm{C} 18$ & 97 & 2 & Yes & 0.09 & - & 0.12 & Yes & 1 & 25 & 3 & 75 & 0 & 0 \\
\hline
\end{tabular}

The symbol "\&" between two markers indicates isobaric compounds with the same molecular weight. (D), derivatized and (U) underivatized (see text for details). For abbreviations of analytes, see legend of Table 1.

${ }^{a}$ This column indicates an override $(\mathrm{O} / \mathrm{R})$ of the target range first element ( $99 \%$ ile of the cumulative normal population) to increase sensitivity and reduce a significant risk of false negative results.

${ }^{b}$ This column indicates an override $(\mathrm{O} / \mathrm{R})$ of the target range second element (5\% ile of the cumulative disorder range) to increase specificity and reduce the occurrence of false positive results.

a preliminary indication of the magnitude of results a laboratory may expect to encounter in an affected newborn. On the other hand, the utility of disorder ranges is not limited to the definition of a cutoff target range. For example, the median value of a disorder range could be used as a more objective alternative to "panic values," which are used inconsistently by many programs on the basis of mostly anecdotal and/or arbitrary information. After verification by a repeat analysis of the same specimen, a value that exceeds the median of the disorder range (e.g., a
C8 concentration of $7 \mu \mathrm{mol} / \mathrm{L}$ or a C14:1 concentration of $1.8 \mu \mathrm{mol} / \mathrm{L}$ in the presence of a characteristic profile for MCAD and VLCAD deficiency, respectively) could become a valid reason to question the wisdom of collecting a repeat sample (dried blood spot) instead of proceeding directly to confirmatory testing by biochemical, enzymatic, and molecular means. Several days could be saved in the process, increasing the probability of preventing a first symptomatic event in the undiagnosed newborn, an episode that may have severe consequences. 
The process described in this study is not complete and will continue until the goal of collecting 50 or more cases of each possible condition has been met. Notably, the number of conditions detectable by the analysis of amino acids and acylcarnitines will continue to grow, too. ${ }^{35,36}$ Furthermore, there are several improvements planned for future implementation. The highest priorities are to statistically validate the override process in response to overlaps, and the exclusion of extreme outliers from the calculation of ranges. This work is already in progress (Ryu et al., unpublished results) and will greatly improve the strength and clinical validity of the target ranges. On the other hand, the outcome of this analysis is likely to result in much tighter ranges, and consequently, a greater proportion of cutoff values will fall outside the suggested interval. For example, a preliminary analysis of the first 1300 cases with MCAD suggests that the target range for octanoylcarnitine (C8) would change from $0.21-0.70 \mu \mathrm{mol} / \mathrm{L}$ to just $0.33-0.38 \mu \mathrm{mol} / \mathrm{L}(95 \%$ confidence interval). When applicable, this statistical revision will take into consideration as a determining factor the growing number of available second tier tests. ${ }^{37-42}$ These tests are performed on the same specimen submitted for the primary screening, with no additional patient contact, targeting informative analytes, which are not included in the primary screening.

Traditionally, conditions with essentially identical biochemical phenotypes have been lumped together on the assumption of almost indistinguishable profiles. Although that is a more than likely reality, participants will be asked to assign their cases, whenever possible, to either one condition of a pair, for example, either long-chain L-3-hydroxy dehydrogenase deficiency or trifunctional protein deficiency, ${ }^{43}$ or methylmalonic acidemia due to either mutase deficiency or belonging to the complementation groups $\mathrm{Cbl} \mathrm{A}$ and $\mathrm{Cbl} \mathrm{B} .{ }^{44}$ Another improvement will be the gradual introduction of condition subtypes based on clinical or molecular criteria, similar to the arrangement already in place where carnitine palmitoyltransferase Ia deficiency patients with the common P479L mutations ${ }^{45,46}$ are shown separately from the other patients with the same condition but different genotypes. MCAD, for example, will be split in three categories: homozygosity for the common mutation ( $A 985 G / A 985 G)$, compound heterozygosity with one $A 985 G$ allele ( $A 985 \mathrm{G} /$ other), and homozygosity or compound heterozygosity with no $A 985 G$ allele (other/other). ${ }^{47}$ Similarly, sorting of cases with isovaleric acidemia will be based on the presence of the $A 282 \mathrm{~V}$ allele, which is found frequently in patients detected by newborn screening. ${ }^{48}$ Other conditions to be split in multiple subtypes are SCAD deficiency (based on profiles of pathogenic mutations and common polymorphisms $)^{49,50}$ and homocystinuria (based on pyridoxine responsiveness). ${ }^{51}$

The data in this publication are deliberately kept at a global level, with no possibility to attribute any of them to a single participant. This is far from the reality of the tools accessible to the users on the R4S website, where up-to-date personalized reports, called comparison tools, are available to analyze the behavior of every percentile and cutoff value in the context of the collective experience. Each participant can generate a report where cutoff values are flagged as "clinically validated" when they meet two conditions: (a) they are within the target range and (b) they fall within the 25th-75th percentile range of all cutoff values. At the same time, special emphasis is placed on cutoff values standing at either the highest or lowest ranking among all sites. The rationale of highlighting such outliers is that corrective action could ensue, leading to an adjustment to a more realistic level. As another laboratory is consequently placed in the same outlier position, this process has been very effective in reducing extreme anomalies and narrowing the distribution curve.

On the basis of an encouraging trend of increased interest in recent months, it is worthwhile noting that the R4S project is hardly limited to laboratory personnel and could be beneficial to the practice of all professionals involved at different stages of the newborn screening system. It could be used to assess and monitor performance, investigate challenging cases by means of postanalytical interpretive tools, and access educational material. For example, since 2007, 139 individuals have attended a week-long training course, which is open to all active users (offered with no registration fee) as an opportunity to improve postanalytical skills, acquire familiarity with the tools of the R4S website, and network with other users. Many US users have received funding for travel and lodging from other Regional Collaboratives. Moreover, MS/MS is just one of eight live applications on the newborn screening domain (Fig. 5). Two of them (lysosomal storage diseases and severe combined immunodeficiency) are supported in part by a contract from the Newborn Screening Translational Research Network (www. nbstrn.org). The vision behind this expansion is to create an infrastructure of identical applications for each of the current and future metabolite-based newborn screening tests, i.e., not based on molecular methods. Access to these applications is

Welcome to the NBS Domain

\section{MS/MS}

SCID

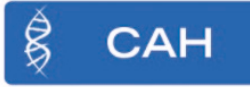

\section{BIOT}

\section{MS/MS [2]}

\section{LSD}

Fig. 5. Live applications on the newborn screening domain on the R4S website. Abbreviations are as follows (in alphabetical order): ALD, X-linked adrenoleukodystrophy (administrative oversight of this application is provided by Silvia Tortorelli, MD, PhD, Mayo Clinic College of Medicine); BIOT, biotinidase deficiency (Tina Cowan, PhD, Stanford University; Robert Grier, PhD, and Barry Wolf, MD, PhD, Wayne State University Medical School); $\mathrm{CAH}$, congenital adrenal hyperplasia (Piero Rinaldo, MD, PhD, Mayo Clinic College of Medicine; Kyriakie Sarafoglu, MD, University of Minnesota); $\mathrm{CH}$, congenital hypothyroidism (unassigned); LSD, lysosomal storage diseases (Dietrich Matern, MD, Mayo Clinic College of Medicine); MS/MS [2], routine second specimen of newborn screening by tandem mass spectrometry (Marzia Pasquali, PhD, University of Utah); NBS, newborn screening; SCID, severe combined immunodeficiency (Roshini Abraham, PhD, Mayo Clinic College of Medicine; Mei Baker, MD, Wisconsin State Laboratory of Hygeine; Amy Brower, PhD, American College of Medical Genetics; Michele Caggana, PhD, New York State Department of Health; Anne Comeau, PhD, University of Massachussetts; and Fred Lorey, PhD, California Department of Public Health). 
stratified from a curator role, with complete access to all data and profiles, to the same read/write and read-only roles found in the MS/MS application. Based on our experience to date, it is critical to identify curators who are content experts, willing and capable of monitoring the quality of the submissions coming in, and to provide feedback to less experienced users.

In conclusion, the R4S collaborative project has paved the way to a collegial and transparent process for clinical validation of newborn screening by MS/MS and potentially of any other laboratory tests for rare disorders if a comparable level of cooperation could be reproduced. The critical factors behind the unanticipated expansion of the collaborative project to become a worldwide initiative have been the gain of mutual trust among participants, the belief of equal standing of all sites regardless of the magnitude of their contributions, and the vision to create tools that motivate users to be actively involved. Indeed, users of the collaborative project have contributed data as they believed that there was tangible value being added to their professional practice. As the project continues, even greater participation is needed, and every effort will be made to welcome new sites and users.

\section{ACKNOWLEDGMENTS}

This work was supported by a Grant (U22MC03963) to the Region 4 Genetics Collaborative from the Health Resources and Service Administration (HRSA) of the Maternal and Child Health Bureau (MCHB) Cooperative Agreement and by the T. Denny Sanford Professorship Fund, Mayo Clinic College of Medicine. Additional sites have contributed limited sets of data. The United States: Alaska, Illinois, and South Dakota; other countries: Japan, Malaysia, Kingdom of Saudi Arabia, Spain, Switzerland, and United Arab Emirates.

\section{AUTHOR AFFILIATIONS}

From the ${ }^{1}$ Mayo Clinic College of Medicine, Rochester, Minnesota; ${ }^{2}$ Michigan Public Health Institute, Okemos, Michigan; ${ }^{3}$ Children's Hospital of Orange County, Orange, California; ${ }^{4}$ Dubai Genetics Centre, Dubai, United Arab Emirates; ${ }^{5}$ Pennsylvania Department of Health, Exton, Pennsylvania; ${ }^{6}$ Karolinska Universitetssjukhuset Huddinge, Stockholm, Sweden; ${ }^{7}$ Oklahoma State Department of Health, Oklahoma City, Oklahoma; ${ }^{8}$ Sapienza University of Rome, Rome, Italy; ${ }^{9} \mathrm{Al}-$ berta Health Services, Edmonton, Alberta, Canada; ${ }^{10}$ Hawaii Department of Health, Honolulu, Hawaii; ${ }^{11}$ Université de Sherbrooke, Sherbrooke, Quebec, Canada; ${ }^{12}$ Wisconsin State Laboratory of Hygiene, University of Wisconsin, Madison, Wisconsin; ${ }^{13}$ Screeningzentrum Hessen, Giessen, Germany; ${ }^{14}$ State Hygienic Laboratory at the University of Iowa, Iowa City, Iowa; ${ }^{15}$ University of Colorado, Aurora, Colorado; ${ }^{16}$ Centre Hospitalier Universitaire de Liège, Liège, Belgium; ${ }^{17}$ Sheffield Children's NHS Foundation Trust, Sheffield, England, United Kingdom; ${ }^{18}$ Indiana Newborn Screening Laboratory, Indianapolis, Indiana; ${ }^{19}$ New York State Department of Health, Albany, New York; ${ }^{20}$ South Carolina Department of Health and Environmental Control, Columbia, South Carolina; ${ }^{21}$ Azienda Ospedaliera Universitaria Integrata di Verona, Verona, Italy; ${ }^{22}$ Missouri Public Health Laboratory, Jefferson City, Missouri; ${ }^{23}$ NeoGen Labs, Bangalore, Karnataka, India; ${ }^{24}$ Delaware Public Health Laboratory, Smyrna, Delaware; ${ }^{25}$ University Department of Pediatrics, G. Gaslini Institute, Genova, Italy; ${ }^{26}$ Public Health Department, Basque Government, Bilbao, Spain; ${ }^{27}$ Hospital Clínico Universitario, Santiago de Compostela, Spain; ${ }^{28}$ Children's Hospital of Eastern Ontario, Ottawa, Ontario, Canada; ${ }^{29}$ Ohio Department of Health, Columbus, Ohio; ${ }^{30}$ Puerto
Rico Newborn Screening Program, San Juan, Puerto Rico; ${ }^{31}$ Hospices Civils de Lyon, Lyon, France; ${ }^{32}$ National Taiwan University Hospital, Taipei, Taiwan; ${ }^{33}$ Tennessee Department of Health Laboratory Services, Nashville, Tennessee; ${ }^{34}$ General University Hospital in Prague, Prague, Czech Republic; ${ }^{35}$ Fundação Ecumênica de Proteção ao Excepcional, Curitiba, Brazil; ${ }^{36}$ Fundación para el estudio de las enfermedades neurometabólicas, Buenos Aires, Argentina; ${ }^{37}$ INTA, Universidad de Chile, Santiago, Chile; ${ }^{38}$ Università degli Studi di Foggia, Foggia, Italy; ${ }^{39}$ California Department of Public Heath, Richmond, California; ${ }^{40}$ Semmelweis University, Budapest, Hungary; ${ }^{41}$ Washington State Department of Health, Shoreline, Washington; ${ }^{42}$ University Medical Center, Utrecht, The Netherlands; ${ }^{43}$ Hospital Virgen del Rocio, Sevilla, Spain; ${ }^{44}$ Università di Padova, Padova, Italy; ${ }^{45}$ Ospedale Umberto I Nocera Inferiore, Salerno, Italy; ${ }^{46}$ University of Athens School of Pharmacy, Athens, Greece; ${ }^{47}$ Indiana University School of Medicine, Indianapolis, Indiana; ${ }^{48}$ Florida Newborn Screening Program, Jacksonville, Florida; ${ }^{49}$ Colorado Department of Public Health and Environment, Denver, Colorado; ${ }^{50}$ Carlos Haya University Hospital, Málaga, Spain; ${ }^{51}$ National Institute for Public Health and the Environment, Bilthoven, The Netherlands; ${ }^{52} \mathrm{New}$ England Newborn Screening Program, Boston, Massachussetts; ${ }^{53}$ West Virginia Department of Health and Human Resources, South Charleston, West Virginia; ${ }^{54}$ Cairo University Faculty of Medicine, Cairo, Egypt; ${ }^{55}$ Arkansas Department of Health, Little Rock, Arkansas; ${ }^{56}$ Louisiana Office of Public Health Laboratory, Metairie, Louisiana; ${ }^{57}$ Kentucky Department for Public Health, Frankfort, Kentucky; ${ }^{58}$ Landspitali-University of Iceland, Reykjavik, Iceland; ${ }^{59}$ University of North Carolina, Chapel Hill, North Carolina; ${ }^{60}$ APAE, São Paulo, Brazil; ${ }^{61}$ Women's and Children's Hospital, Adelaide, South Australia, Australia; ${ }^{62}$ University Hospital Miguel Servet, Saragoza, Spain; ${ }^{63}$ Princess Margaret Hospital, Perth, Western Australia, Australia; ${ }^{64}$ Wayne State University Medical School, Detroit, Michigan; ${ }^{65}$ Jiaotong University School of Medicine, Shanghai, China; ${ }^{66}$ Department of Health and Mental Hygiene, Baltimore, Maryland; ${ }^{67}$ Georgia Department of Human Resources Laboratory, Atlanta, Georgia; ${ }^{68}$ Center for Disease Control, Atlanta, Georgia; ${ }^{69}$ ARUP Laboratories, Salt Lake City, Utah; ${ }^{70}$ Emory University, Atlanta, Georgia; ${ }^{71}$ Minnesota Department of Health, St. Paul, Minnesota; ${ }^{72}$ Mississippi State Department of Health, Jackson, Mississippi; ${ }^{73}$ Statens Serum Institute, Copenhagen, Denmark; ${ }^{74}$ Texas Department of State Health Services, Austin, Texas; ${ }^{75}$ Faculty of Medicine, Memorial University, St. John's, Newsfoundland, Canada; ${ }^{76}$ Instituto de Investigaciones Biomédicas UNAM, Mexico City, Mexico; ${ }^{77}$ Vermont Department of Health, Burlington, Vermont; ${ }^{78}$ University Hospital of Obstetrics and Gynecology "Maichin dom," Sofia, Bulgaria; ${ }^{79}$ Arizona Department of Health Services, Phoenix, Arizona; ${ }^{80}$ KK Women's and Children's Hospital, Singapore, Singapore; ${ }^{81}$ Shodair Children's Hospital, Helena, Montana; ${ }^{82}$ University of Szeged, Szeged, Hungary; ${ }^{83}$ Medical University of Vienna, Vienna, Austria; ${ }^{84}$ Northwest University, Potchefstroom, South Africa; ${ }^{85}$ Neolab SA, Athens, Greece; ${ }^{86}$ Saint Joseph University, Beirut, Lebanon; ${ }^{87}$ LabPlus, Auckland Hospital, Auckland, New Zealand; ${ }^{88}$ Shimane University School of Medicine, Shimane, Japan; ${ }^{89}$ IWK Health Centre, Halifax, Nova Scotia, Canada; ${ }^{90}$ University Children's Hospital, Heidelberg, Germany; ${ }^{91}$ Meyer Children's Hospital, Florence, Italy; ${ }^{92} \mathrm{New}$ Hampshire Department of Health and Human Services, Concord, New Hampshire; ${ }^{93}$ Sungkyunkwan University School of Medicine, Seoul, South Korea; ${ }^{94}$ University of Saskatchewan, Regina, Canada; ${ }^{95}$ Instituto de Seguridad Social, Montevideo, Uruguay; ${ }^{96}$ The Children's Hospital at Westmead, Sydney, New South 
Wales, Australia; ${ }^{97}$ Health Resource Research Administration, Bethesda, Maryland; ${ }^{98}$ Nebraska Department of Health and Human Services, Lincoln, Nebraska; ${ }^{99}$ Connecticut Department of Public Health Laboratory, Hartford, Connecticut; ${ }^{100}$ Kansas Health \& Environmental Laboratories, Topeka, Kansas; ${ }^{101} \mathrm{Cli}-$ niques universitaires Saint-Luc, Université Catholique de Louvain, Bruxelles, Belgium; ${ }^{102}$ Children's University Hospital, Dublin, Ireland; ${ }^{103}$ Royal Children's Hospital, Herston, Queensland, Australia; ${ }^{104}$ State of Rhode Island Department of Health, Providence, Rhode Island; ${ }^{105}$ University of Athens Medical School, Athens, Greece; ${ }^{106}$ Maine Center for Disease Control and Prevention, Augusta, Maine; ${ }^{107}$ Biomedicine SA, Athens, Greece; ${ }^{108}$ Institute of Mother and Child, Warsaw, Poland; ${ }^{109}$ Università degli Studi di Napoli "Federico II," CEINGE-Biotecnologie Avanzate, Napoli, Italy; ${ }^{110}$ Association of Public Health Laboratories, Washington, District of Columbia; ${ }^{111}$ University of Utah, Salt Lake City, Utah; ${ }^{112}$ New Jersey Department of Health and Senior Services, Trenton, New Jersey; ${ }^{113}$ International Society of Newborn Screening, Glenmont, New York; ${ }^{114}$ Oslo University Hospital, Oslo, Norway; ${ }^{115}$ Murdoch Children's Research Institute, Melbourne, Victoria, Australia; ${ }^{116}$ Virginia Division of Consolidated Laboratory Services, Richmond, Virginia; ${ }^{117}$ Pathology Queensland, Herston, Queensland, Australia; ${ }^{118}$ Hospital Nacional de Niños, San José, Costa Rica; ${ }^{119}$ Wyoming Department of Health, Cheyenne, Wyoming; ${ }^{120} \mathrm{AB}$ Sciex, Concord, Ontario, Canada; ${ }^{121}$ University of Alabama at Birmingham, Birmingham, Alabama; ${ }^{122}$ National Institute of Health Doutor Ricardo Jorge, Porto, Portugal; ${ }^{123}$ Cadham Provincial Laboratory, Manitoba Health, Winnipeg, Manitoba, Canada; ${ }^{124}$ Hospital Universitario Virgen de la Arrixaca, El Palmar, Spain; ${ }^{125}$ Universidad Autónoma de Nuevo León, Monterrey, Mexico; ${ }^{126}$ North Dakota Department of Health, Bismark, North Dakota; ${ }^{127}$ Yale University School of Medicine, New Haven, Connecticut; ${ }^{128}$ Michigan Department of Community Health, Lansing, Michigan; ${ }^{129}$ Oregon State Public Health Laboratory, Hillsboro, Oregon; ${ }^{130}$ Children's \& Women's Health Center, Vancouver, British Columbia, Canada; ${ }^{131}$ Hamad Medical Corporation, Doha, Qatar; ${ }^{132}$ University of Maryland School of Medicine, Baltimore, Maryland; ${ }^{133}$ Tanyalcin Medical Lab Selective Newborn Screening and Metabolism Unit, Izmir, Turkey; ${ }^{134}$ University of Iowa Children's Hospital, Iowa City, Iowa; ${ }^{135}$ Instituto Nacional de Pediatria Secretaría de Salud, Mexico City, Mexico; ${ }^{136}$ American College of Medical Genetics, Bethesda, Maryland; ${ }^{137}$ Virginia Department of Health, Richmond, Virginia; ${ }^{138} \mathrm{Al}-$ der Hey Children's NHS Foundation Trust, Liverpool, United Kingdom; and ${ }^{139}$ Lancet Laboratories, Johannesburg, South Africa.

\section{REFERENCES}

1. Watson MS, Mann MY, Lloyd-Puryear MA, Rinaldo P, Howell RR, editors. Newborn screening: toward a uniform screening panel and system [Executive summary]. Genet Med 2006;8(suppl):1S-11S

2. Sebelius K, 2010. Available at: http://www.hrsa.gov/heritabledisorderscommittee/ correspondence/response5_21_2010.pdf. Accessed November 1, 2010.

3. Puryear M, Weissman G, Watson M, Mann M, Strickland B, van Dyck PC. The regional genetic and newborn screening service collaboratives: the first two years. Ment Retard Dev Disabil Res Rev 2006;12:288-292.

4. Rinaldo P, Zafari S, Tortorelli S, Matern D. Making the case for objective performance metrics in newborn screening by tandem mass spectrometry. Ment Retard Dev Disabil Res Rev 2006;12:255-261.

5. Sweetman L, Millington DS, Therrell BL, et al. Naming and counting disorders (conditions) included in newborn screening panels. Pediatrics 2006;117:S308-S314.

6. Editorial. Separated at birth. Nat Genet 2004;36:1127.

7. Natowicz M. Newborn screening-setting evidence-based policy for protection. N Engl J Med 2005;353:867.
8. Moyer VA, Calonge N, Teutsch SM, Botkin JR. Expanding newborn screening: process, policy, and priorities. Hastings Cent Rep 2008;38: 32-39

9. Howell RR. Every child is priceless: debating effective newborn screening policy. Hastings Cent Rep 2009;39:4-6.

10. Tarini BA, Christakis DA, Welch HG. State newborn screening in the tandem mass spectrometry era: more tests, more false-positive results. $\mathrm{Pe}$ diatrics 2006;118:448-456.

11. Frazier DM, Millington DS, McCandless SE, et al. The tandem mass spectrometry newborn screening experience in North Carolina: 1997-2005. J Inherit Metab Dis 2006;29:76-85.

12. Wilcken B, Wiley V, Hammond J, Carpenter K. Screening newborns for inborn errors of metabolism by tandem mass spectrometry. $N$ Engl $\mathrm{J} \mathrm{Med}$ 2003;348:2304-2312.

13. American College of Medical Genetics. Act sheets and confirmatory algorithms. Available at: www.acmg.net. Accessed November 29, 2010

14. Downs SM, van Dyck PC, Rinaldo P, et al. Improving newborn screening laboratory test ordering and result reporting using health information exchange. J Am Med Inform Assoc 2010;17:13-18.

15. Turgeon $\mathrm{C}$, Magera MJ, Allard $\mathrm{P}$, et al. Combined newborn screening for succinylacetone, amino acids, and acylcarnitines in dried blood spots. Clin Chem 2008;54:657-664.

16. Tortorelli S, Turgeon CT, McHugh DMS, et al. Two-tier approach to the newborn screening of methyleneteratrahydrofolate reductase deficiency and other re-methylation disorders by tandem mass spectrometry. J Pediatr 2010;157:271-275.

17. Perkin Elmer. StepOne ${ }^{\circledR}$ newborn screening. Available at: www. perkinelmergenetics.com. Accessed November 29, 2010.

18. Chace DH, Millington DS, Terada N, Kahler SG, Roe CR, Hofman LF. Rapid diagnosis of phenylketonuria by quantitative analysis for phenylalanine and tyrosine in neonatal blood spots by tandem mass spectrometry. Clin Chem 1993;39:66-71.

19. Khalid JM, Oerton J, Besley G, et al. Relationship of octanoylcarnitine concentrations to age at sampling in unaffected newborns screened for medium-chain acyl-CoA dehydrogenase deficiency. Clin Chem 2010;56:1015-1021.

20. Duran M. Amino acids. In: Blau N, Duran N, Gibson KM, editors. Laboratory guide to the methods in biochemical genetics. Heidelberg: SpringerHeidelberg, 2008:53-89.

21. Allard P, Grenier A, Korson MS, Zytkovicz TH. Newborn screening for hepatorenal tyrosinemia by tandem mass spectrometry: analysis of succinylacetone extracted from dried blood spots. Clin Biochem 2004;37:1010-1015.

22. Magera MJ, Gunawardena ND, Hahn SH, et al. Rapid quantitative determination of succinylacetone in dried blood spots by liquid chromatography tandem mass spectrometry. Mol Genet Metab 2006;88:16-21.

23. Sander J, Janzen N, Peter M, et al. Newborn screening for hepatorenal tyrosinemia: tandem mass spectrometric quantification of succinylacetone. Clin Chem 2006;52:482-487.

24. la Marca G, Malvagia S, Pasquini E, et al. The inclusion of succinylacetone as marker for tyrosinemia type I in expanded newborn screening programs. Rapid Commun Mass Spectrom 2008;22:812-818.

25. la Marca G, Malvagia S, Funghini S, et al. The successful inclusion of succinylacetone as a marker of tyrosinemia type I in Tuscany newborn screening program. Rapid Commun Mass Spectrom 2009;23:3891-3893.

26. Chace DH, Lim T, Hansen CR, De Jesus VR, Hannon WH. Improved MS/MS analysis of succinylacetone extracted from dried blood spots when combined with amino acids and acylcarnitine butyl esters. Clin Chim Acta 2009;407:6-9.

27. Rinaldo P, Matern D. Newborn screening for inherited metabolic disease. In: Hoffmann GF, Zschocke J, Nyhan WL, editors. Inherited metabolic diseases. Berlin: Springer-Verlag, 2010:251-261.

28. Puckett RL, Lorey F, Rinaldo P, et al. Maple syrup urine disease: further evidence that newborn screening may fail to identify variant forms. Mol Genet Metab 2010;100:136-142.

29. Gallagher RC, Cowan TM, Goodman SI, Enns GM. Glutaryl-CoA dehydrogenase deficiency and newborn screening: retrospective analysis of a low excretor provides further evidence that some cases may be missed. Mol Genet Metab 2005;86:417-420.

30. Ficicioglu C, Coughlin CR 2nd, Bennett MJ, Yudkoff M. Very long-chain acyl-CoA dehydrogenase deficiency in a patient with normal newborn screening by tandem mass spectrometry. J Pediatr 2010;156:492-494.

31. Bhattacharya K, Khalili V, Wiley V, Carpenter K, Wilcken B. Newborn screening may fail to identify intermediate forms of maple syrup urine disease. J Inher Metab Dis 2006;29:586.

32. Chace DH. Method for interpreting tandem mass spectrometry data for clinical diagnosis. US Patent No. 6,455,321 B1, September 24, 2002.

33. Lindner M, Ho S, Kölker S, Abdoh G, Hoffmann GF, Burgard P. Newborn screening for methylmalonic acidurias - optimization by statistical parameter combination. J Inherit Metab Dis 2008;31:379-385.

34. Rinaldo P, Cowan TM, Matern D. Acylcarnitine profile analysis. Genet Med 2008;10:151-156. 
35. Carrozzo R, Dionisi-Vici C, Steuerwald U, et al. SUCLA2 mutations are associated with mild methylmalonic aciduria, Leigh-like encephalomyopathy, dystonia and deafness. Brain 2007;130:862-874.

36. Van Hove JL, Saenz MS, Thomas JA, et al. Succinyl-CoA ligase deficiency: a mitochondrial hepatoencephalomyopathy. Pediatr Res 2010;68:159-164.

37. Matern D, Tortorelli S, Oglesbee D, Gavrilov D, Rinaldo P. Reduction of the false positive rate in newborn screening by implementation of MS/MS-based second tier tests: the Mayo Clinic experience (2004-2007). J Inherit Metab Dis 2007;30:585-592.

38. la Marca G, Malvagia S, Pasquini E, Innocenti M, Donati MA, Zammarchi E. Rapid 2nd-tier test for measurement of 3-OH-propionic and methylmalonic acids on dried blood spots: reducing the false-positive rate for propionylcarnitine during expanded newborn screening by liquid chromatographytandem mass spectrometry. Clin Chem 2007;53:1364-1369.

39. Oglesbee D, Sanders KA, Lacey JM, et al. Second-tier test for quantification of alloisoleucine and branched-chain amino acids in dried blood spots to improve newborn screening for maple syrup urine disease (MSUD). Clin Chem 2008;54:542-549.

40. Forni S, Fu X, Palmer SE, Sweetman L. Rapid determination of C4acylcarnitine and $\mathrm{C} 5$-acylcarnitine isomers in plasma and dried blood spots by UPLC-MS/MS as a second tier test following flow-injection MS/MS acylcarnitine profile analysis. Mol Genet Metab 2010;101:25-32.

41. Shigematsu Y, Hata I, Tajima G. Useful second-tier tests in expanded newborn screening of isovaleric acidemia and methylmalonic aciduria. $J$ Inherit Metab Dis 2010;33:S283-S288.

42. Turgeon CT, Magera MJ, Cuthbert CD, et al. Simultaneous determination of total homocysteine, methylmalonic acid, and 2-methylcitric acid in dried blood spots by tandem mass spectrometry. Clin Chem 2010;56:1686-1695.
43. Ibdah JA, Bennett MJ, Rinaldo P, et al. A fetal fatty acid oxidation disorder causes maternal liver disease of pregnancy. N Engl J Med 1999;340:17231731.

44. Fowler B, Leonard JV, Baumgartner MR. Causes of and diagnostic approach to methylmalonic acidurias. J Inherit Metab Dis 2008;31:350-360.

45. Greenberg CR, Dilling LA, Thompson GR, et al. The paradox of the carnitine palmitoyltransferase type Ia P479L variant in Canadian Aboriginal populations. Mol Genet Metab 2009;96:201-207.

46. Gessner BD, Gillingham MB, Birch S, Wood T, Koeller DM. Evidence for an association between infant mortality and a carnitine palmitoyltransferase 1A genetic variant. Pediatrics 2010;126:945-951.

47. Smith EH, Thomas C, Gavrilov D, et al. Allelic diversity in MCAD deficiency: the biochemical classification of 54 variants identified during 5 years of ACADM sequencing. Mol Genet Metab 2010;100:241-250.

48. Ensenauer R, Vockley J, Willard JM, et al. A common mutation is associated with a mild, potentially asymptomatic phenotype in patients with isovaleric acidemia diagnosed by newborn screening. Am J Hum Genet 2004;75:11361142.

49. Nagan N, Kruckeberg KE, Tauscher AL, Snow-Bailey K, Rinaldo P, Matern D. The frequency of short-chain acyl-CoA dehydrogenase (SCAD) gene variants in the US American population and correlation with the $\mathrm{C} 4$ acylcarnitine concentration in newborn blood spots. Mol Gen Metab 2003;78:239-246.

50. Pedersen PB, K lvraa S, K lvraa A, et al. The ACADS gene variation spectrum in 114 patients with short chain acyl-CoA dehydrogenase (SCAD) deficiency is dominated by missense variations leading to protein misfolding at the cellular level. Hum Genet 2008;124:43-56.

51. Skovby F, Gaustadnes M, Mudd SH. A revisit to the natural history of homocystinuria due to cystathionine beta-synthase deficiency. Mol Genet Metab 2010;99:1-3. 